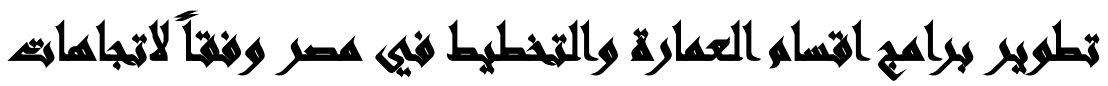

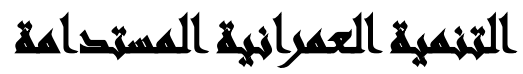

[४]

أحمد يحيي إسماعيل(')- محمد مصطفي محمد عبد الحفيظ(؟)

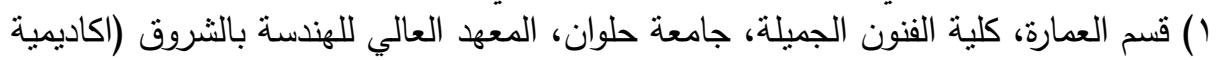

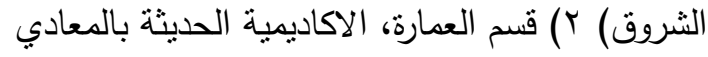

\section{المستصنص}

في ضوء زيادة ارتباط الجامعات بالمجتمع وتأثثرها المباشر في جميع المجالات سواء

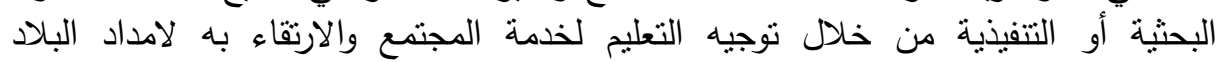

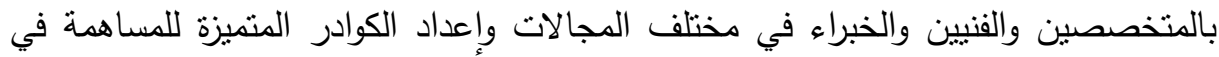

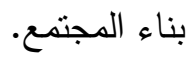

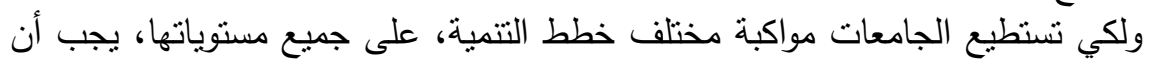

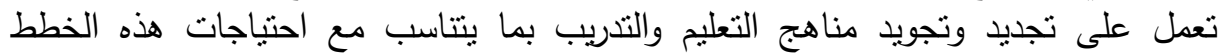
التتموية، سواء من سرعة في الأداء وكفاءة التتفيذ.

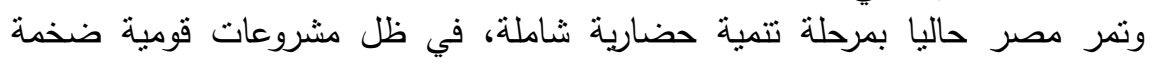

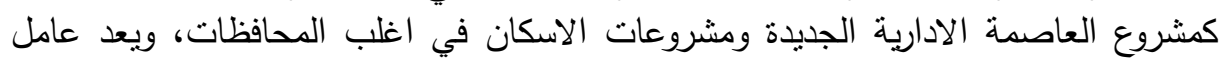

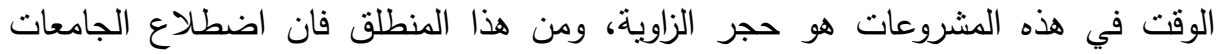

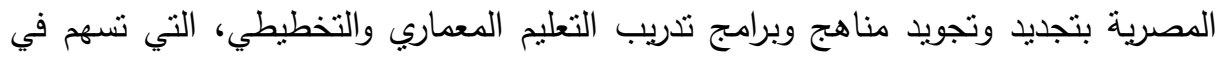

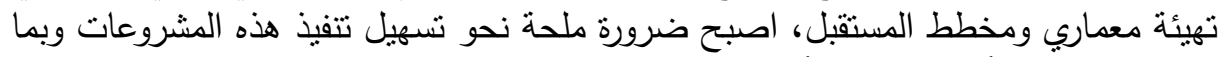

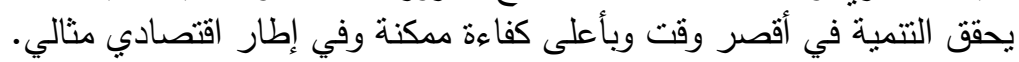

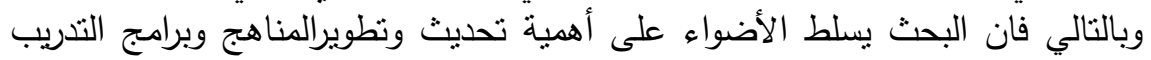

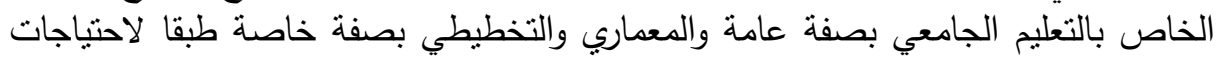

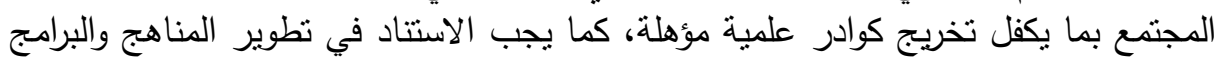

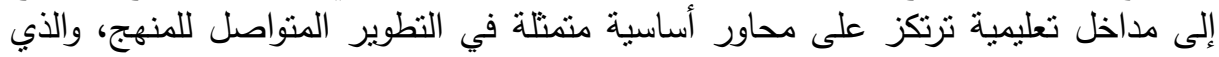
يهدف لإقامة جسور بين النظرية والتطبيق والتخصئ تركس.

الكلمات المفتاحية: التتمية العمرانية - التتمية المستدامة التعامية - اقسام العمارة - اقسام التخطيط تطوير البرامج - التعليم الجامعي- التعليم المعماري. 


\section{مهند}

أن التعليم المعماري الجامعي بوجه عام يهدف إلى إمداد الطالب بمجالات المعرفة التي تتتاسب مع احتياجات المجتمع، والبيئة المحيطة، وإلى الفهم المنكامل للإحتياجات الإنسانية .

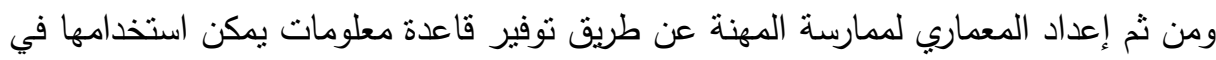
الممارسة المهنية بكفاءة وفاعلية في المجالات الهندسية المختلفة (تصميم معماري، إعداد الرسومات التنفيذية، الإشراف على التنفيذ، تتفيذ الأعمال الهندسية، البحث العلمي......). ولكن هل التعليم المعماري الحالي ملائم لاحتباجات ممارسة المهنة على النطاق المحلي

لذا فان البحث يمثل محاولة تقييم مدى توافق محتوى مناهج التعليم المعماري الجامعي

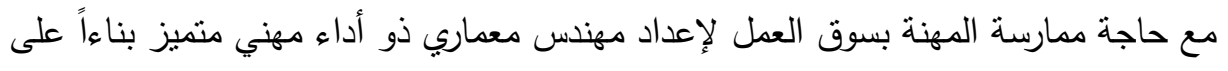
دراسة تحليلية للمستوى التعليمي المعماري الجامعي بمصر بالجامعات الحكومية والجامعات والمعاهد الخاصة. وبتحليل أداء المعماريين بسوق العمل (المكاتب الهندسبة، الثركات والهيئات الهندسية، رؤى أصحاب العمل والمهندسين الممارسين ) يتم تحديد ايجابيات وسلبيات التعليم المعماري

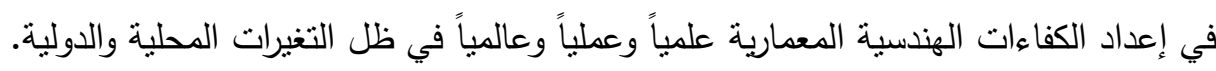

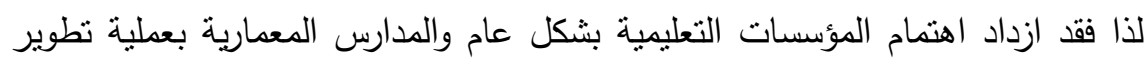

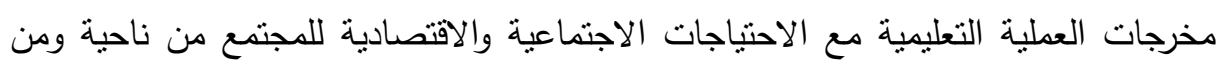
ناحية أخرى مع متطلبات سوق العمل (المحلي والإقليمي والعالمي).

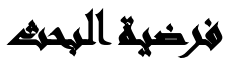

أن مناهج التعليم المعماري في العديد من الجامعات المصرية حاليا لا تتوافق بشكل كامل مع احتياجات السوق وبرامج التتمية العمرانية. المشكلة البحثية: تمنل الفجوة الكبيرة بين ما يدرسه الطالب في سنوات الدراسة المعمارية وما يواجها من منطلبات في المهند الخربج بسوق العمل بشكل عملي المشكلة الاساسية،

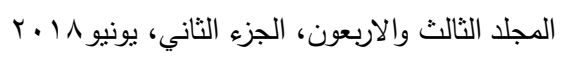


اضافة الي القصور الواضح في تشخيص العوامل المؤثرة في تطوير برامج التعليم المعماري

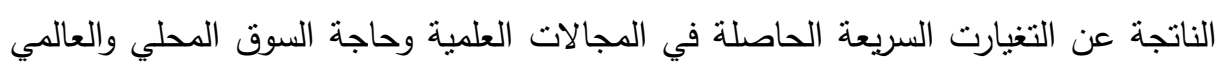
وبرنامج التتمية. هدف البحث: التحليل الدقيق لنقاط ضعف بعض المناهج التقليدية، لتحديد المعايير الملائمة لأساليب ونظم بناء وتطوير المناهج التطبيقية وكذلك دراسة لبعض النظم والأساليب العالمية

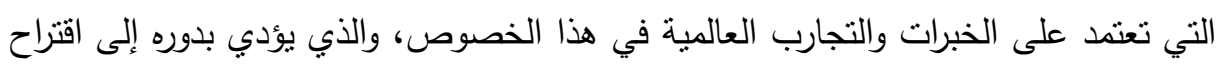

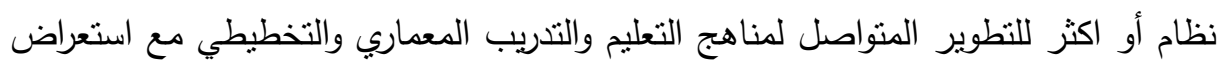

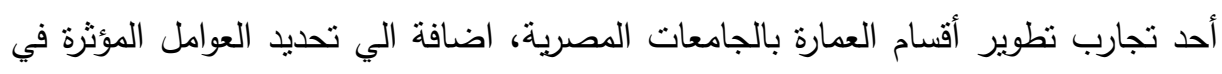

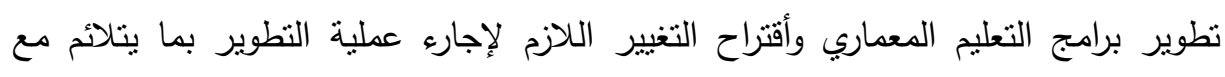
التطوارت الحديثة وحاجة السوق برامجن منهج البحث: ا ـ بناء قاعدة معلوماتية عن محددات تطوير برامج التعليم المعماري والناتجة عن التغيارت السريعة الحاصلة في مجالات المتغيارت العلمية وحاجة السوق المحلي وبرنامج التتمية. r. تغطية الفجوة الخاصة بمناهج التعليم المعماري من خلال نطبيق اساليب المشاركة المجتمعية. r. استخلاص النتائج وتحديد الاستتناجات والتوصيات. آراء المعماريين المحليين والعالميين عن مناهج التعليم المعماري: إن عملية

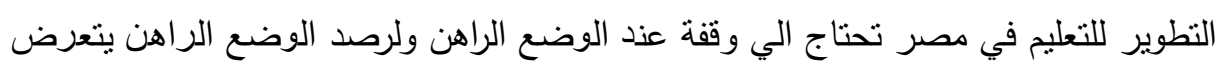

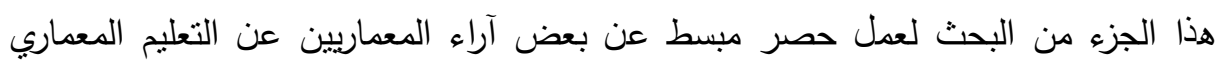
الحالي، والنقاط الاساسية المؤثرة علي التعليم المعماري في ظل التغيرات العالمية والمحلية. فيري بعض المعماريين أمثال سوليفان ان التعليم المعماري مسئولا عن العقم الفني

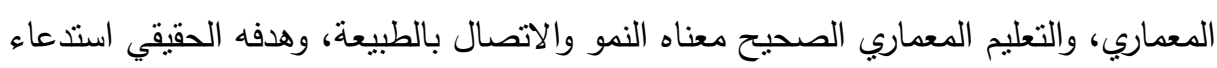
واستخراج المواهب. سوليفان: هو المعماري الرائد لمدرسة شيكاجو وواحد من اعلام العمارة في النصف الثاني من القرن التاسع عشر وله أهمية في توجيهها وتطويرها).

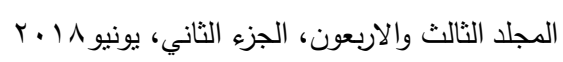


كما يري الاستاذ الدكتور كمال رياض ان هناك عدم توافق بين المناهج التعليمية في

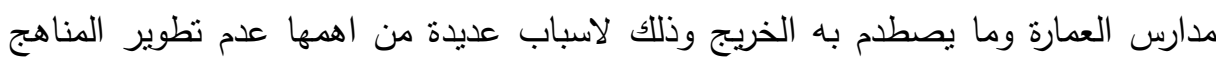

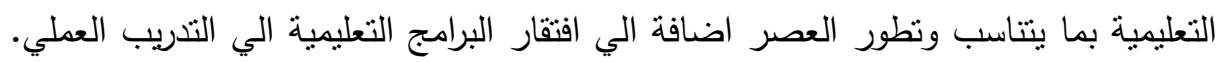

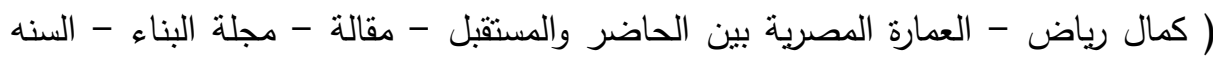

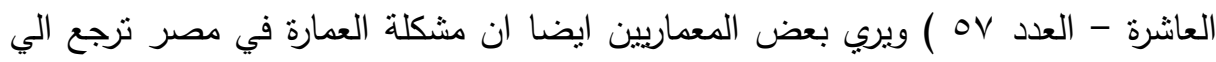

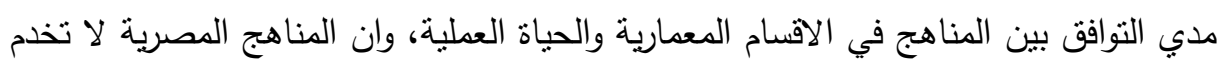
المجال الخاص بالتتفيذ ومتابعة اعمال الاشراف فالمعماري المصري يري بعض التصام مواد البناء والآلات المستخدمة في عمليات التتفيذ لاول مرة عند تخرجه من الجامعة والعمل في الموقع.

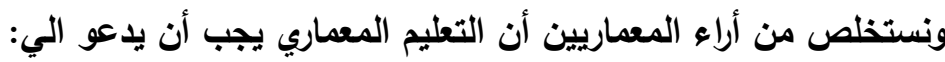
- التدريب العملي ومواكبة متغيرات العصر والاشتراك في الندوات والمؤتمرات والتفرغ للبحوث. - أهمية ربط المناهج في اقسام العمارة بالحياة العملية.

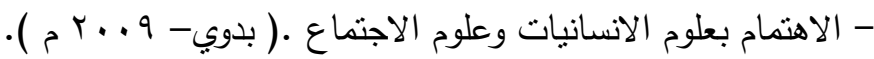
دراسة تحليلية لمحتوي المناهج الدراسية المعمارية بالجامعات: ينتمي خريجي اقسام العمارة الي اكثر من •A قسم من الجامعات الحكومية او الجامعات والمعاهد الخاصة علي مستوي الجهورية، ونسبة اقسام العمارة بالجامعات الحكومية الي الجامعات والمعاهد

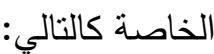

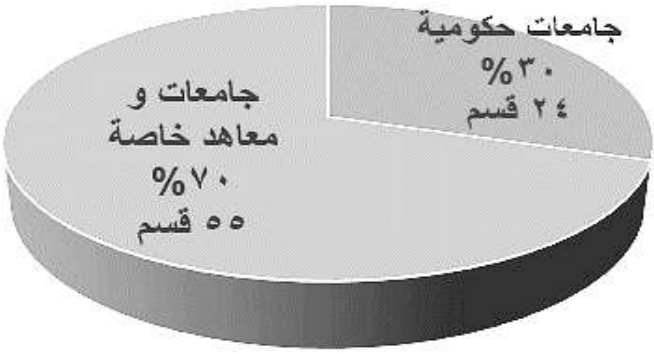

شكل(1) (1) نسبة اقسام العمارة بالجامعات الحكومية والجامعات والمعاهد الخاصة بمصر المصدر: نقابة المهندين المصرية - دليل الجامعات المقيدة بالنقابة شعبة الهندسة المعمارية .المجلس 


$$
\begin{aligned}
& \text { ويمكن تقسيم مناهج الدراسة باقسام العمارة الي مجموعات: (جدول - 1) } \\
& \text { 1 - مجموعة العلوم التمهيدية } \\
& \text { r- مجموعة الرسم والتصميم المعماري والمواد التصميمية } \\
& \text { ب- مجموعة تاريخ ونظريات العمارة } \\
& \text { ـ - مجموعة علوم الهندسة المدنية والانثائية } \\
& \text { 0- مجموعة علوم الانثاء المعماري والتحكم البيئي } \\
& \text { צ- مجموعة المواد التخطيطية وتتسيق المواقع }
\end{aligned}
$$

\begin{tabular}{|c|c|}
\hline المواد التى تشملها المجموعة & 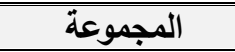 \\
\hline 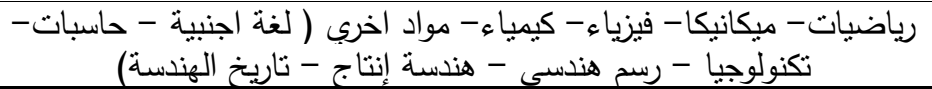 & 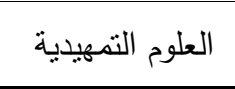 \\
\hline تصميم معماري - ظل وظلال ومنظور - رسم نظري - تتكيل مرئى & التصمبم المعماري \\
\hline تاريخ العمارة والفن - نظريات العمارة & تاريخ ونظريات \\
\hline نظريات الانشاءات - تكنولوجيا البناء- خواصات المواد واختباراتها - منشات - منشات & المدنية والانشائية \\
\hline 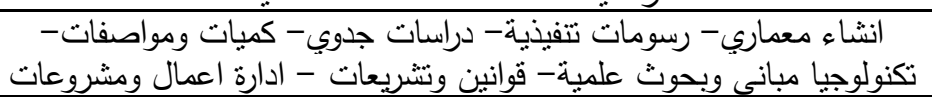 & ت البنولُوجيا وعلوم \\
\hline دراسة تخطيط واسكان - تاريخ التخطيط & التخطية واقتسيق \\
\hline انظمة الصوت- انظمة الاضياءه- انظمة التهوية والتذفئة- علوم انسانية- تركيبة & 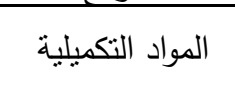 \\
\hline 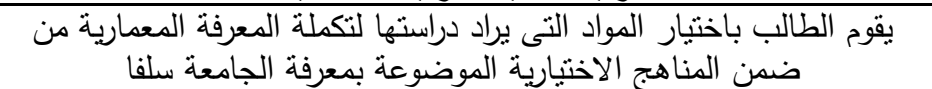 & 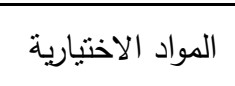 \\
\hline
\end{tabular}

V- مجموعة المواد التكميلية (صوتيات واضاءه، نركيبات فنية، هندسة صحية، علوم انسانية)

$$
\text { 1- مجموعة المواد الاختبارية. }
$$

ومن خلال التحليل المقارن للنسب المئوية لهذه المجموعات في اقسام العمارة المختلفة

يمكن استتناج السلبيات والايجابيات في اقسام العمارة بالجامعات المختلفة موضع الدراسة.

وقد نم اختيار كلا من الجامعات الثالية كنماذج للاراسة :كلية الهندسة جامعة القاهرة .-

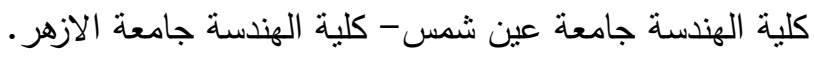

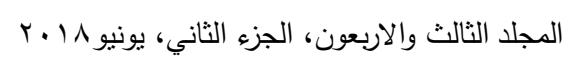


- التعليم المعماري الجامعي في الاكاديمية العربية للعلوم والتكنولوجيا والنقل البحري .التعليم المعماري الجامعي في كلية الهندسة جامعة مصر الدولية. جدول(ץ): نسبة توزيع المواد الدراسية باقسام العمارة بالجامعات الحكومية والجامعات والمعاهد الهديه

\begin{tabular}{|c|c|c|c|c|c|c|c|}
\hline اختيارية & تكميلية & تخطيط & تكنولوجيا & هندسية & نظريات & تصميم & الجامعة \\
\hline$\% 0$ & $\% \backslash r, 0$ & س,rו) & $\% \backslash 0, \wedge$ & \%) r, r & $\% 1 \cdot, \wedge$ & $\%$ \%, 0 & جامعةة \\
\hline$\% \vee, 0$ & $\% \wedge, \varepsilon$ & $\% \vee, q$ & $\% r r, q$ & $\%) \cdot, \varepsilon$ & $\% 1$. & $\% r r, q$ & عين شمسة \\
\hline \%r,r & $\% \backslash r, \varepsilon$ & $\% q, \vee$ & $\% \backslash 9, \varepsilon$ & $\%) \varepsilon, r$ & $\% 1 \cdot, 1$ & \% ו, & الازهرة \\
\hline$\% \backslash \vee, 乏$ & $\% 0,7$ & $\% \vee, 0$ & $\% r \cdot, 0$ & $\% q, r$ & $\% 9,9$ & $\% \curlyvee q, \wedge$ & الاكاديمبة العربية \\
\hline$\% 0,9$ & $\% r, q$ & ---- & $\% \backslash \vee, 7$ & $\% \backslash,, \varepsilon$ & $\% \backslash 0,1$ & $\% \leq 0,1$ & جامعة \\
\hline
\end{tabular}

نتائج تحليل منوسط الساعات التدريسية لمجموعات المواد الدراسية لاقسام العمارة

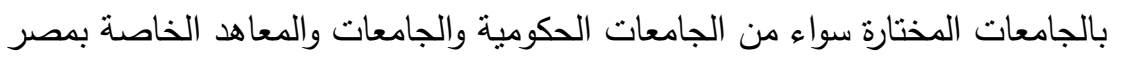
جدول(ץ): نتائج تحليل منوسط الساعات التدريسية لمجموعات المواد الدراسية لاقسام العمارة بالجامعات المختارة

\begin{tabular}{|c|c|c|}
\hline 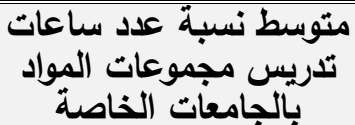 & 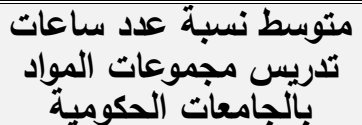 & مجموعات المواد \\
\hline$\% \leqslant 0$ & $\%$ \%r & التصميح المعماري والرسم \\
\hline$\% 10$ & $\% 1$. & تاربخ ونظربات العمارة \\
\hline$\% 1 Y$ & $\% 1 Y$ & العلوم الهندسية المدنية والانثائية \\
\hline$\% 19$ & $\% 19$ & تكنولوجيا وعلوم البناء \\
\hline----- & $\%$ & التخطيط وتتسيق المواقع \\
\hline$\% 7$ & $\% 9$ & المواد التكميلية \\
\hline$\% 1$. & $\% \Lambda$ & المواد الاختياربة \\
\hline
\end{tabular}


تحليل مناهج التعليم المعماري التقليدية باقسام العمارة: المواد المعمارية والتخطيطية والمواد المكملة لأقسام العمارة بكليات الهندسة يمكن إيجازها بالترتيب التالي (مواد أساسية، تخصصية، تكميلية)( جدول ع ):

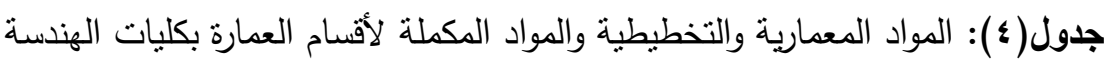

\begin{tabular}{|c|c|c|c|}
\hline مواد تكميلية & مواد تخصصية & مواد أساسية & الالسنة \\
\hline مساحة، تحليل & نظريخات عمارة، ظل ومنظور ، نظري، & تصميم معماري، إنشاء معماري & 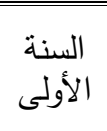 \\
\hline تكليف إنشاءات، الهواء، تحواص تربة، & 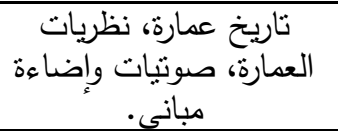 & 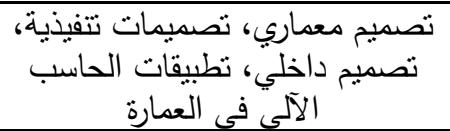 & الثانية \\
\hline خرسانة مسلحة، إنشاء معدنية & مبانى، كميات ومواصن، نشريعات & تطبيقات معماري، تصميمات الحيق فتئيذية العمارة & الثنالثة \\
\hline & تخطيط مدن، إسكان، إدارة & تشروع بكالوريوس، معماري، تصميمات نتفيذية، معماري، & الرابعة \\
\hline
\end{tabular}

باستعراض المناهج التعليمية في أقسام العمارة في مصر نجد أنها متثابهة تقريبا مع بعض

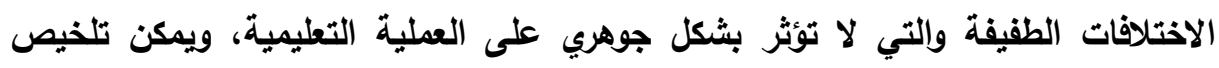
أوجه القصور كما يلي:

1- عدم وجود تكامل وتتاسق بين المواد التي تدرس من ناحية المحتوى والتوقيت وعدد

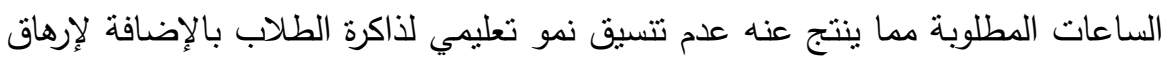
الطالب بمجهود كمي مضعف لا يؤدي إلى تفكير منتاسق أو دقيق.

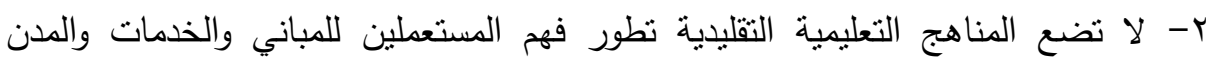
واحتباجاتهم.

r- عدم وضوح اندماج وتكامل العوامل البيئية، الاقتصادية، البيئة المحلية، والتراث الحضاري، والفكر العالمي في التطبيق العملي للتنفيذ من خلال ربط هذه العناصر الأساسية بمشتقاتها وتحليل ثوابتها وعناصر تطويرها لضمان استمراريتها والثخصية المميزة لها. 
ع- ارتباط التعليم المعماري بكليات الهندة في اغلب الجامعات وبالتالي أصبح التعليم المعماري ؛ سنوات فقط والذي يضطر الطالب المعماري من دراسة السنة الإعدادي والتي لئي لا تمثل أي إضافة له سواء من المواد الدراسية أو العملية.

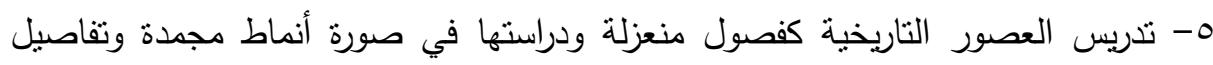
قياسية هو مجرد سرد لمعاني ووصف نمطي أكاديمي بعيد تماما عن الفهم الحقيقي لهذه الحضارات والقيم المعمارية فيها.

צ- التقسيم الزائد للمعرفة المطلوب إيصالها للطالب في صورة مواد دراسية كل منها مسنقل عن الأخر، مما يجعل الطالب غير واع للارتباط المطلوب بينها، ويقلل من فرصة استيعاب المعرفة بصورتها الثاملة. V- عدم وجود مقررات تدريبية وميدانية كافية أدت للانفصال الواضح بين مناهج التعليم النظري والعلمي. ^- تفتقد المناهج التعليمية الحالية إلى علم إدارة المشروعات المعمارية أثناء مراحل تتفيذها، وكذللك المناهج التي تهنم ببرامج الصيانة وتتشيل الأعمال المعمارية. 9- تفقتد المناهج لكيفية تدريب الطالب على التعامل مع التخصصات الأخرى المكملة له في تلئي ممارسة مهنته وفهر سلوكيات مهنته وإدارة مشروع متكامل أثثاء المرحلة التصميمية

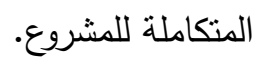

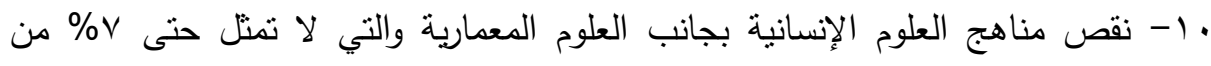
إجمالي العلوم الأساسية.

1) - تدريس العمارة بالجامعات المصرية يعتمد على نظم وأساليب (نظرية، تدريبية، عملية)

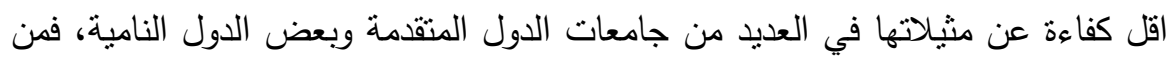

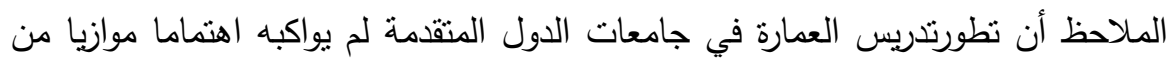
قبل الجامعات المصرية سواء بنطوير نظم التدريس أو التدريب المستمر أو النواحي العملية لمراحل العملية التصميمية والتتفيذية. 
r ا - تبعية نظام تعليم العمارة لنظام التعليم الهندي الأمر الذي جعله تعليما تقنيا دون

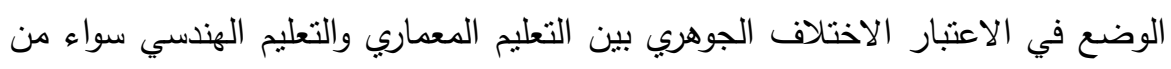
ناحية المدة أو المحتوى الدراسي.

rا - وجود ثغرات في المناهج وخلوها من برامج التدريب العملي ومنها على سبيل المثال:

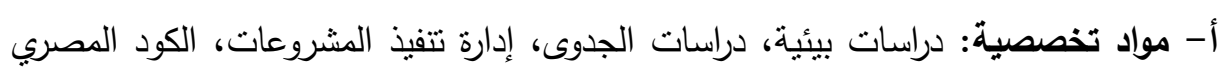
والكود الأمريكي للمباني FEDIC، العقود والمواصفات، دراسات اجتماعية وعمرانية، إدارة

$$
\text { شركات المقاولات. }
$$

ب-مواد اختيارية : دراسات متقدمة بتكييف الهواء، شبكات المرافق العامة، الهندسة الصحية. ع ا- بالرغم من وجود محاولات فردية متفرقة لتحقيق جزء من التطوير المنشود في العملية

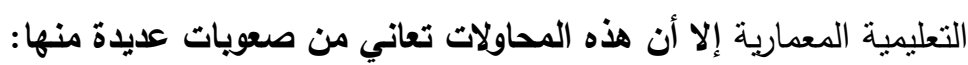

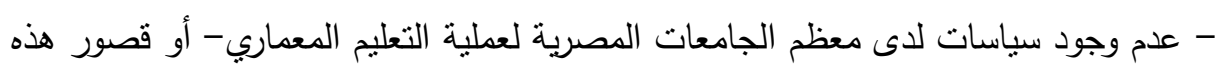
السياسات.

- قصور الإمكانات الأساسية المطلوبة لتطوير نظام التعليم المعماري خاصة بالأجهزة والمراجع والدوريات العلمية والتي تحتاج لإمكانيات مادية عالية. - اعتماد أساليب تدريس المواد على الأساليب التقليدية

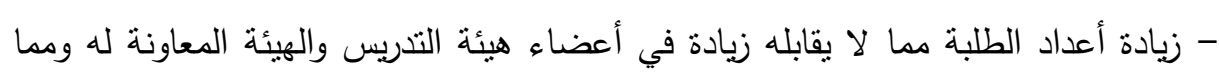
يقلل فرصة الاحتكاك المباشر بين طرفي العملية التعليمية وكذلك التقييم الصحيح

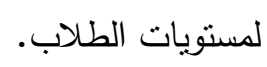

- عدم توافر أعضاء هيئة التدريس لبعض التخصصات الدقيقة منل (الصوت، الضوء،

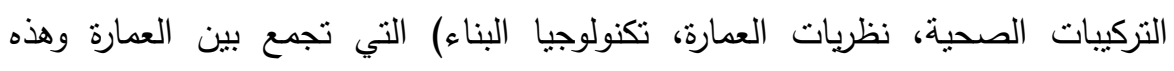

$$
\text { التخصصات الاقيقة }
$$

- عزوف أعضاء هيئة التدريس عن التقرغ للتدريس الجاد في أقسام العمارة وتزكية جهدهم الأكبر لمكاتبهم وأعمالهم الخاصة لضعف المرتبات التي تعطيها الجامعة.( كاظم - ـ

$$
\left.(\cdot)^{r} \cdot\right) \leq
$$




\section{أهية التطوير المستمر للمناهج المعمارية والتخطيطية والريط بين النظرية}

والتطبيق: تمثل الجامعات المصدر الرئيسي للمتخصصين والخبراء في جميع المجالات للرقي بأي مجتمع أو دولة، ولكي تتمكن الجامعات من أداء هذا الدور فعليها أن نزيد من قوة

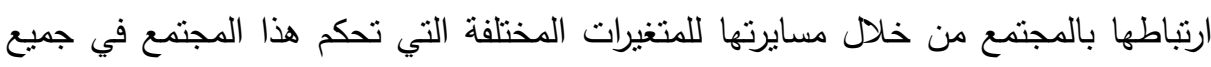
المجالات ولكي تتككن الجامعات من ذلك فلابد أن تعمل على تجديد وتجويد مناهج التعليم والتدريب بما يتلاءم واحتياجات هذه المتغيرات خاصة المتغيرات المتعلقة بخطط النتمية على جميع مستوياتها في أقصر وقت وبأعلى كفاءة. كما أن النظام الحالي لقبول الطلاب في الجامعات المصرية (وبالتالي أقسام العمارة) يؤثر تأثيرا سلبيا على العملية التعليمية وينعكس ذللك سلبيا على المستوى العملي للخريجين. ويعتمد هذا النظام على المجموع بصفة عامة دون الأخذ في الاعتبار إمكانيات الطلاب

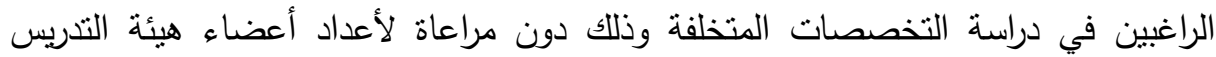
داخل القسم أو احتياجات المجتمع والذي يصادف نقص متزايد في أعداد أعضاء هيئة التدريس وزيادة أعداد الخريجين خاصة في السوق المعمارية، حيث أدى التوسع في قبول

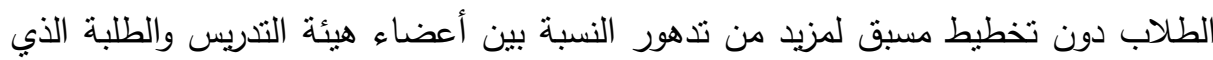
يؤدي بدوره لتراكم السلبيات ولذا يعتبر تطوير نظم التعليم المعماري ضرورة لتلافي السلبيات

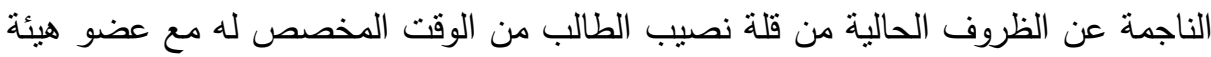
التدريس، انخفاض قدرات الطلاب الفنية ومقدرتهم على الخلق التشكيلي والإبداع المعماري

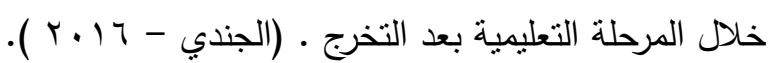
وحيث أن مشكلة العملية التعليمية بالعمارة والتخطيط تعتبر من المشاكل المركبة لأنها ليست مستقلة بذاتها عن البيئة المحيطة بها، وذلك لأن التصميم المعماري يعتبر من أهم العمليات التي تتم داخل هذا المجال، لذلك فان قضيه التصميم المعماري لها جوانب عديدة وهذا لأن التعليم المعماري يحتوي على العديد من الاهتمامات والأنشطة لذلك يجب إيجاد

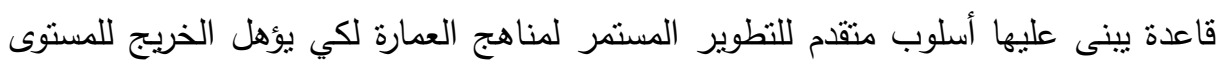


الإبداعي والتقنيالمطلوب حيث أن الملاحظ هو فقدان العمارة المصرية الحديثة للشخصية والقوة

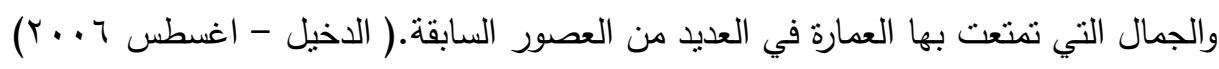
لذلك فان أهمية نطوير التعليم المعماري تكمن في إيجاد التكامل والتفاعل السليم بين المواد المعمارية المختلفة والتتسيق فيما بينها لكي تتصهر جميعها في بوتقة مشروع مترابط الهيط

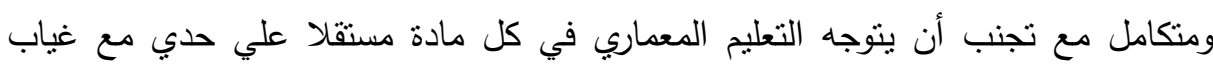

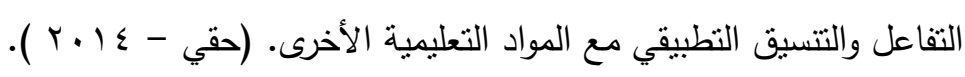
قصور البرامج: يمكن تلخيص بعض عوامل القصور الحاصل بالعديد من البرامج للتعليم المعماري في مجتمعنا التعليمي في ثغرات البرامج التي تعتمد على سبيين رئيسيين:

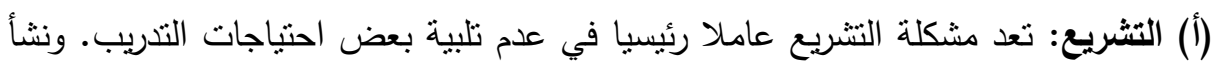

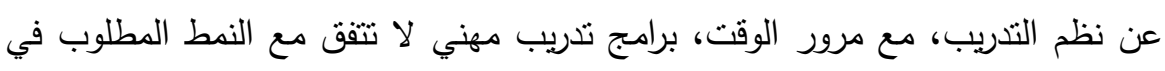

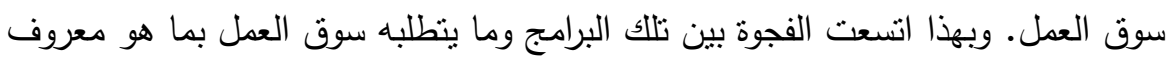
عنه بأنه يسعى للحاق بما يجد من تطورات في حقوله المختلفة. ولم تتوفر التشريعات المناسبة لتلافي الخلل عن طريق الحث على متابعة المستحدثات في سوق العمل لإِدخالها

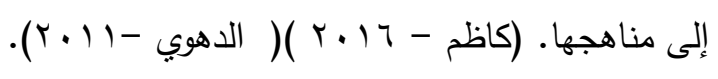

(ب) الاحتياج المحدود: تعاني معظم الأقسام المعمارية والتخطيطية من عجز في الطاقة

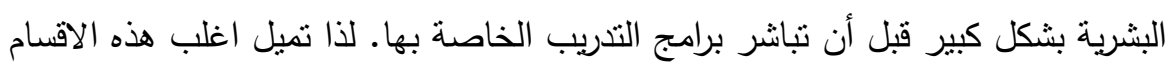

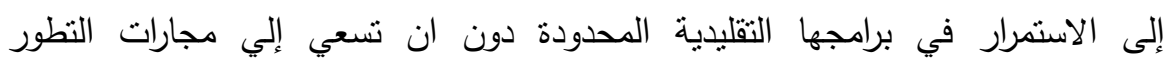

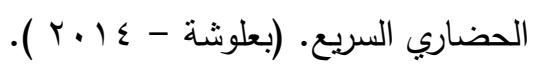

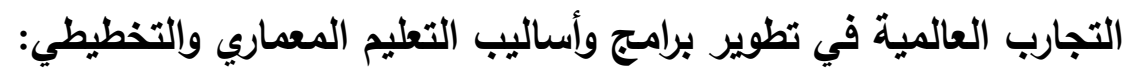
تقديم لأحد أساليب ونظم التطوير المستمر للمناهج التعليمية: يهنم البحث بعرض إحدى نظم تطوير المناهج والتي تهدف لإقامة جسور بين النظرية والتطبيق والذي يسمى نظام الديكم / فهو يعتبر منهجية لتطوير منهج التعليم (DECUM = Developing A Curriculum) التدريب والذي يعطي للطالب القدرة على الالتحاق بسوق العمل دون الحاجة الكبيرة لتدريب

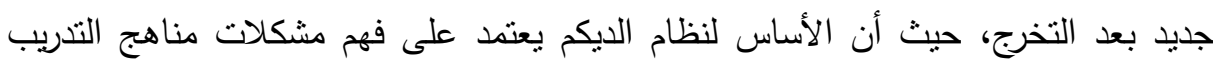


أهداف نظام الديكم [ DACUM ]

* تحديد مدى ملائمة المنهج لحاجة سوق العمل الحقيقية * تحدي الخبرات والمهارات التي يجب أن يحوزها الأفراد للالتحاق بمهنة محددة مدانه * تحديد حاجة المجال من الأفراد المدربين

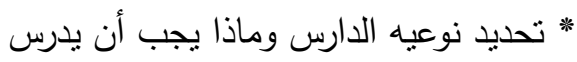

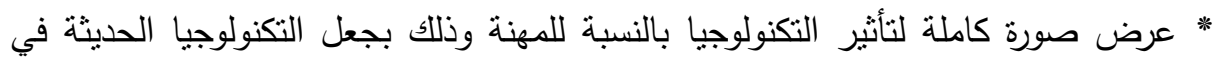
اولويات منطلبات المهنة

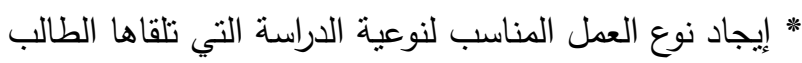

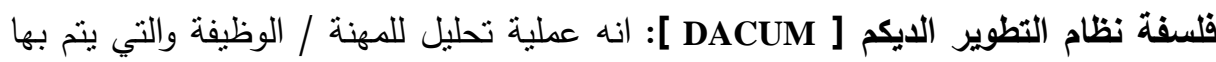

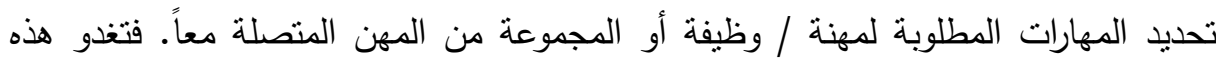

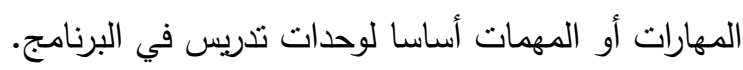
* يتم وصف أي نوع من المهن على نحو أكثر فعالية من خلال المهام التي يقوم بها خبراء لتهاء المهنة. * لكل مهنة محددات واتجاهات يجب نوفرها كي تؤدى على نحو سليم. * المهنيون المتمرسون اقدر على وصف مهنتهم. (Iris Seet , Jan 2008)

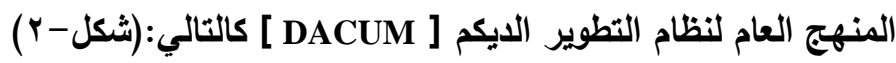
أ- تحليل المهنة ينفذها عمال خبراء في المهنة. ب- يلخص لمهارات المهنة مستخدم لوصفها خطة منهج أو أداة تقويم.

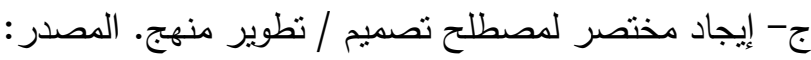




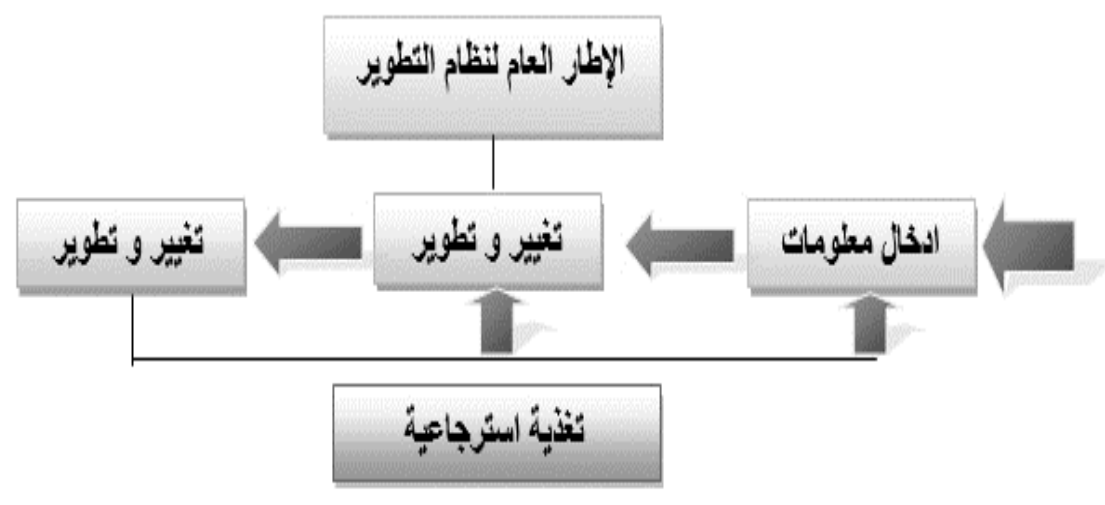

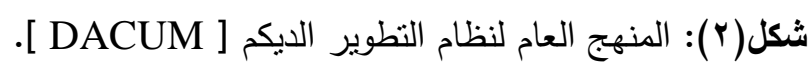

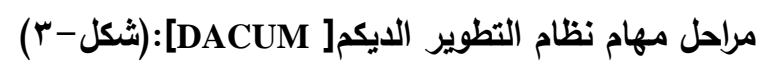
أ- تحليل مهني: تعريف المهارات والمعرفة اللازمة لأداء المهنة حيث يقوم بهائ خبكاء خبراء بالمهنة ب- تصميم الأهداف: تحويل منطلبات السلوك الخاص بالمهارة والمعرفة إلى أهداف تعليمية

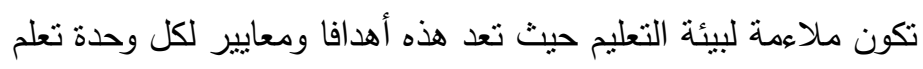

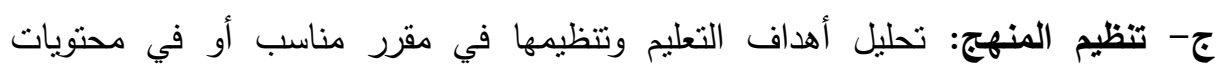
موضوعات أخرى مناسبة ويمكن أن تجزأ هذه بين مجالات ومقررات مختلفة

د- تصميم مواد التعليم: هو مهمة تحتاج إلى جهد كبير لإنجازها وتعتمد على الخبراء للقيام بها هـ - تخطيط البرامج. و - تصميم الاختبارات وإجراءات التقويم.

ز - تدريب المعلمين والمدرسين. Report on Sustainable Urban Agriculture)

Enterprises 2012) 


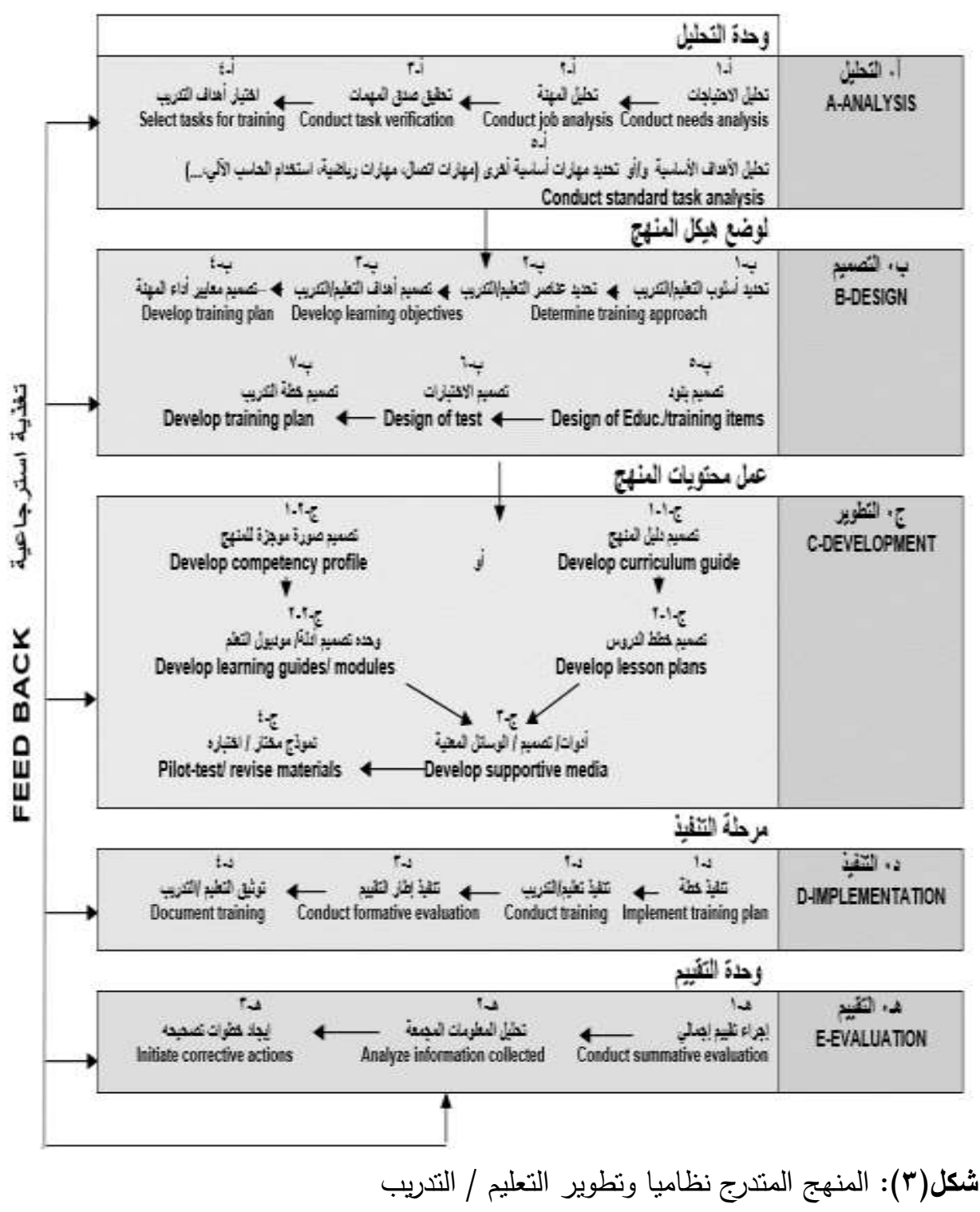


المشاركون في نظام الديكم [ DACUM ]:(شكل - ؛ ) أ- المنسق " Co-Ordinator ": يتم اختباره للأشراف على عملية الديكم.

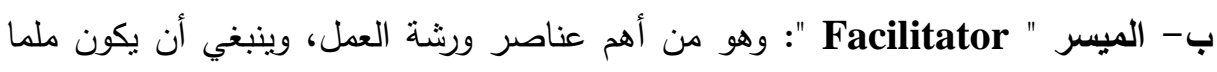
بخلق التفاعل ويتعين أن يكون ألوفا وصبورا وقادرا على صنع القرار ويختار الميسر وندير مسجلا لمشاركته العمل. ج- لجنة الايكم: وتتكون هذه عادة من ^-ـ ا فردا ويتم اختبار أفرادها من مختلف الجهات التي تتوافر فيها المهنة / الوظيفة وفق الثروط الآتية:يعمل الفرد آنئذ في المهنة الوظيفية أو يشرف عليها مباشرة، كفء وذو عقلية متقتحة، يعتبره أقرانه قادرا على العمل كعضو في فريق، يتمتع بالموضوعية وبالثقة. د- لجنة التطوير Development Committee: وتتكون من الميسر (أو المنسق) وشخصين متميزين من لجنة الديكم بالإضافة إلى مدرسين أو ثلاثة من المدرسين

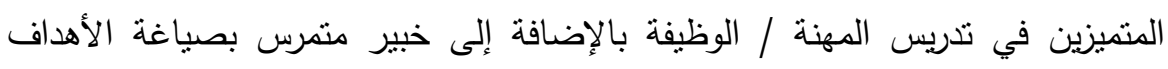

هـ - لجنة استشارية (حسب الحاجة) Advisory committee: وتتكون من رجال الخبرة في المهنة أو المراكز المماثلة لعرض الديكم قبل النهائي عليهم لإبداء ملحوظاتهم. (Niebler , 2012) 


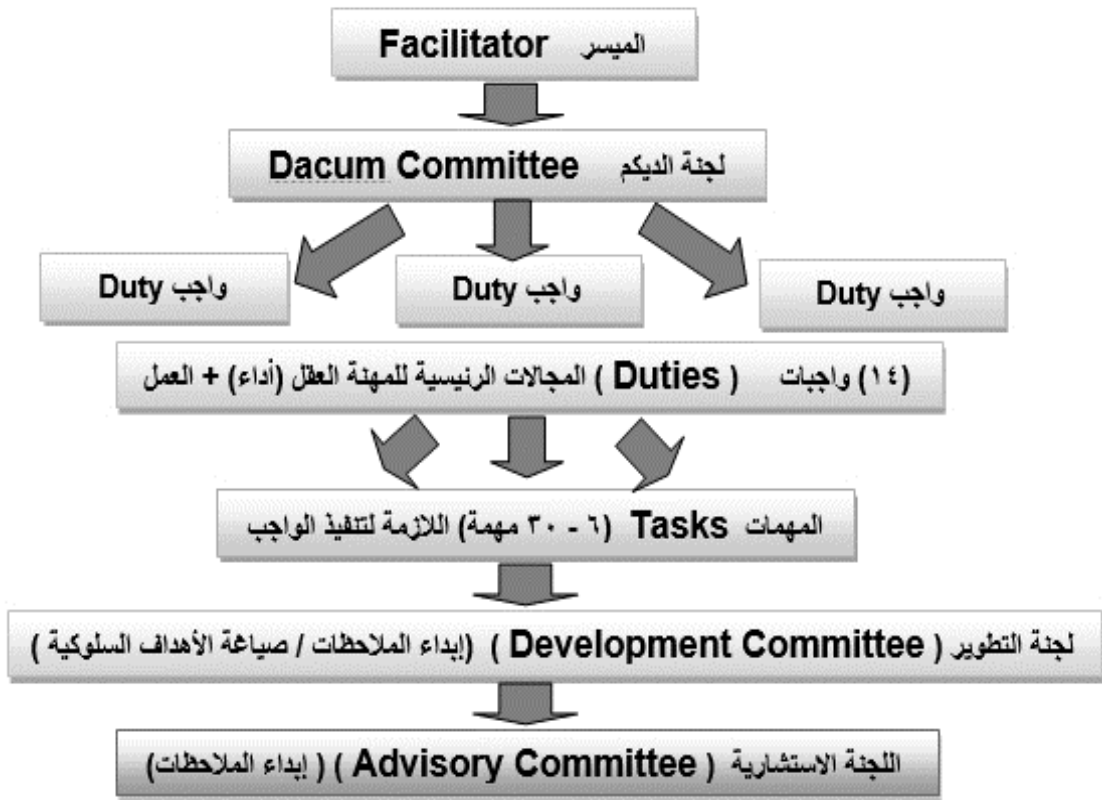

شكل(؛): المشاركون في نظام الديكم [ DACUM ].

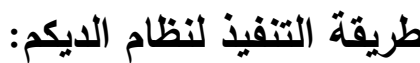
أ- يقدم الميسر للجنة ويشرح مؤهلاته. ب- يقوم الميسر بعقد اجتماع تمهيدي مع لجنة الديكم ويوضح لها عملية الديكم وفلسفته. ج- يقوم أفراد لجنة الديكم بتشجيع من الميسر " ودون أي تدخل منه" بالخطوات الآتية:

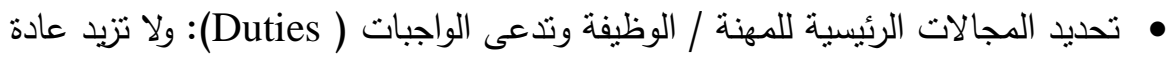

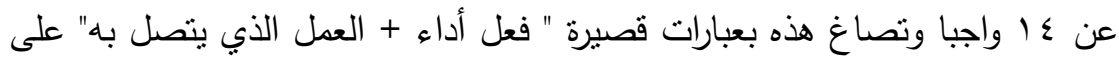

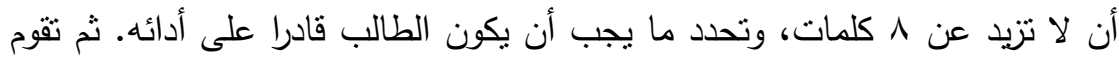

$$
\text { اللجنة بترتيب الواجبات حسب الأهمية. }
$$

• تحليل كل واجب ( Duty ): إلى مجموعة من المهمات Tasks اللازمة لتتفيذ الواجب، وتتراوح عادة بين 7 - . ب مهمة، وتتم الصياغة بعبارات قصيرة ثم يجرى ترتيبها حسب أولوية التنفيذ. 
د- تقوم لجنة التطوير بإبداء ملحوظاتها ويتولى المختص بصياغة الأهداف السلوكية في قالب واضح. د. د.

هـ - يجري عرض النموذج السابق على اللجنة الاستشارية لإبداء ملحوظاتها.

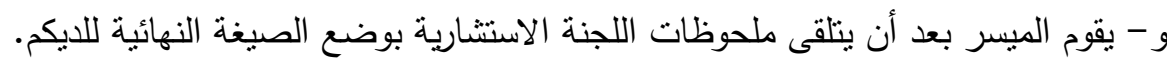
ي - يتم إرسال "ديكم المهنة / الوظيفة" إلى الجهات المختصة للعمل على تطبيقه.

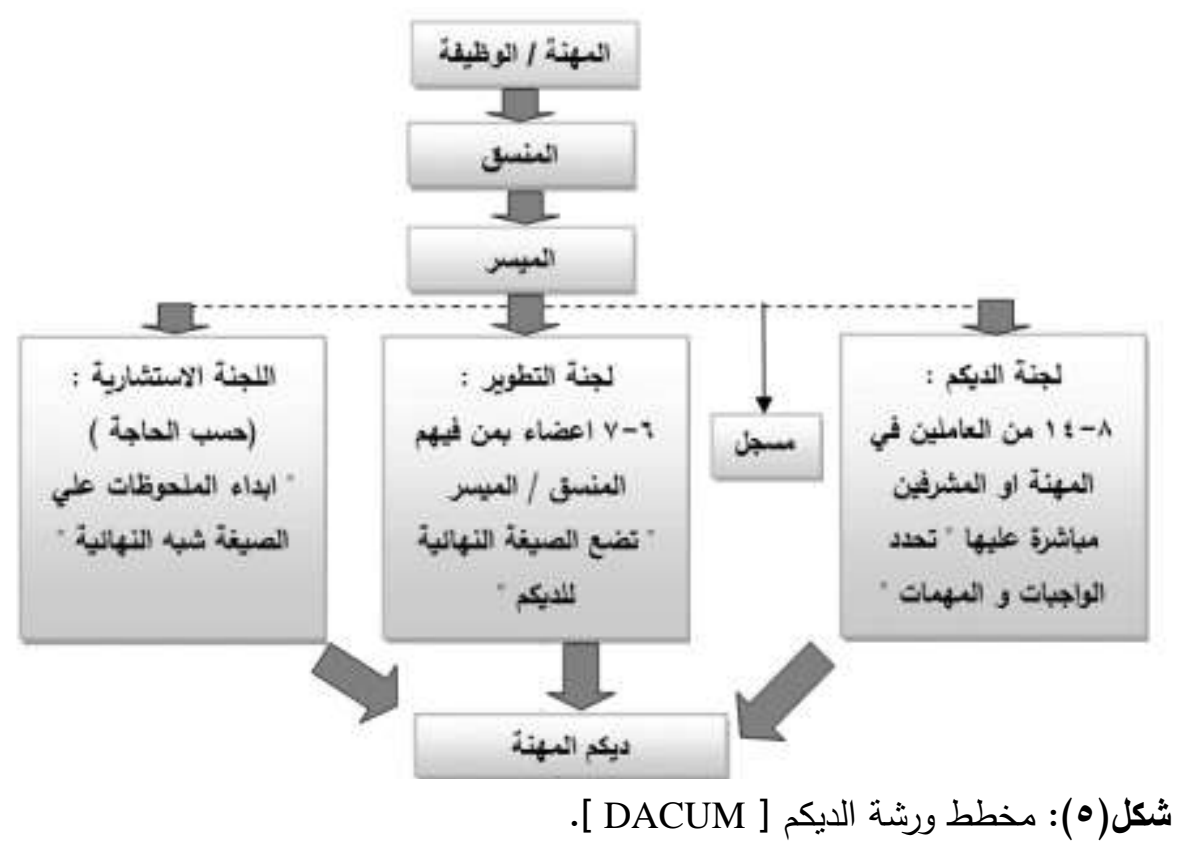

الخبرات السابقة في تطبيق نظام تطوير المناهج التطبيقية:تتعتد الهيئات والمعاهد التالية

بالولايات المتحدة على تطوير نظام الديكم في نطوير مناهجها وأسلوب تدريب: - معهز عمليات الطاقة النووية ( INPO ).

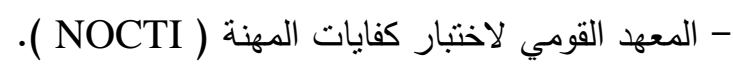

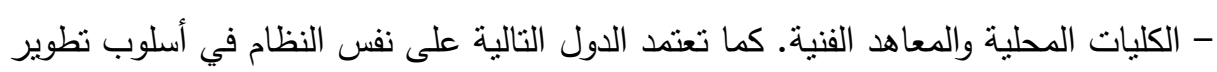
مناهج التعليم أو التدريب ( نيوزلندة - الفلييين - سنغافورة - هولندا - كندا - الكويت). 
معايير وأسس تظوير المناهج المعمارية والتخطيطية وبناء نظم المناهج التطبيقية احتياج سوق العمل: تشهئ مصر حاليا تتمية حضارية أحد دعائمها المحافظة على البيئة، حيث تنثل التتمية العمرانية أحد أجزائها الرئيسية، ويمكن تصنيفها من خلال اتجاهات التنمية

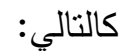
مشاريع فورية حكومية بمشاركة القطاع الخاص: 1- تتمية توشكي وتتمل محطة الرفع، مدينة توشكي الجديدة وتوابعها سواء حضرية أو ريفية. r- r مشروع شرق الثقريعة: ويشمل المنطقة الصناعية وميناء شرق بورسعيد. r-r-مشروع خليج السويس: ويثمل المنطقة الصناعية بخليج السويس وميناء العين السخنئة ع -مشروع تتمية شبه جزيرة سيناء بالإضافة لمحافظات قناة السويس. ه- مشروع شرق العوينات وما يتبعه من امتداد عمراني. آتتمية جنوب الوادي وما بشمله من امتدادات المدن الحالية واستثمارات صناعية ونية وزراعية وتجارية. V- ما بلزم لإتمام هذه المثاريع من خدمات سواء طرق ومحطات كهرباء ومياه ومطارات،

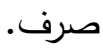

$$
\text { 1- الدئ الجديدة باللتنا وجنوب الوادي. }
$$

$$
\text { 9- البيئة: رفع جودة البيئة بالددن والقرى الحالية. }
$$

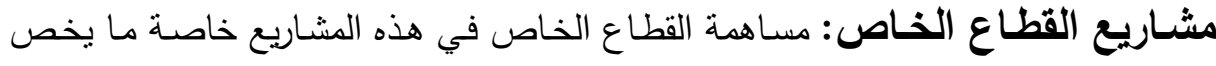
التتمية العرانية من إقامة مجتمعات عمرانية جديدة سواء بالددن الجديدة والمدن والمناطق

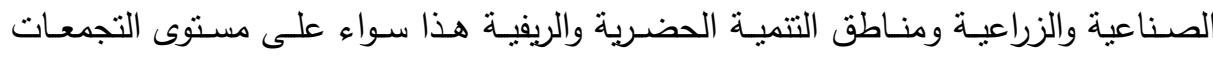
العمرانية لمباني ذات الطابع الخاص (الإدارية، المستشفيات، الدطارات، نجارية) أو المباني العيدي الفردية (سكنية - إدارية، تجارية ). 
اقتراح لمراحل تطوير المناهج التعليمية والتدريبية لأقسام العمارة باستخدام نظام الديكم: 1- اختيار فرق من متخصصين (معماريين مصممين ومنففين ومخططين) في كل المجالات

$$
\text { السابقة. }
$$

r- كل فريق يتكون من r متخصصين من نفس المجال.

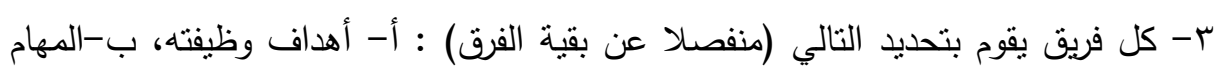
التي يقوم بها لتحقيق هذه الأهداف، ج-المعلومات التي يجب أن تتوافر لديه للقيام بهذه

$$
\text { المهام، د-المعامل والأدوات التي تخدم تحقيق هذه الأهداف. }
$$

ع-يترك كل متخصص يتحدث بطريقته ثم يدون كل معلومة في ورقة فارغة بالترتيب التالي:

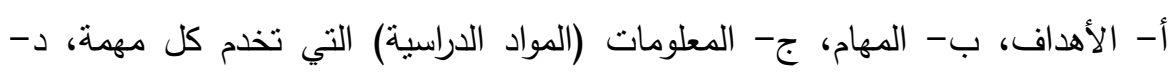

$$
\text { الأدوات والمعدات والمعامل التي تخدم كل مادة. }
$$

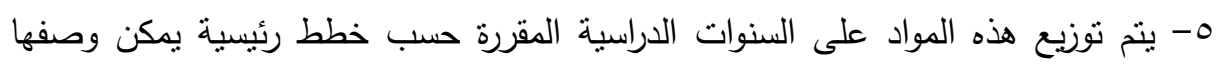

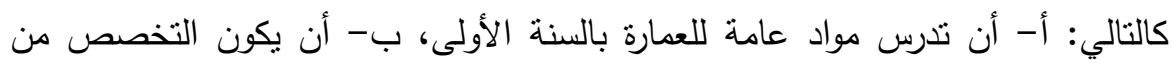

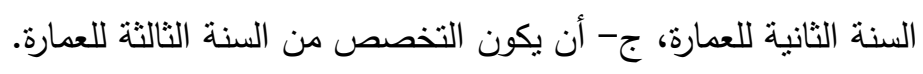

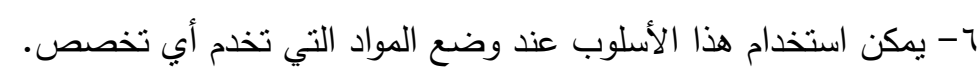

V- يتم تكرار هذه الطريقة كل س-ه سنوات لمواكبه هذا التطور وعمل تقييم لمحتويات المواد.

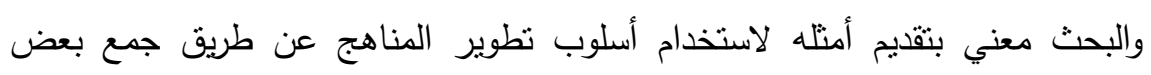

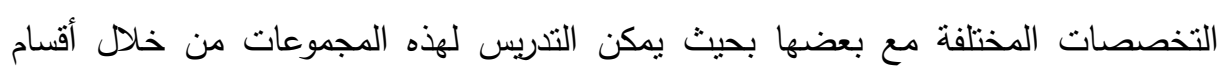

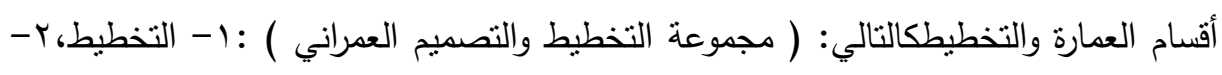

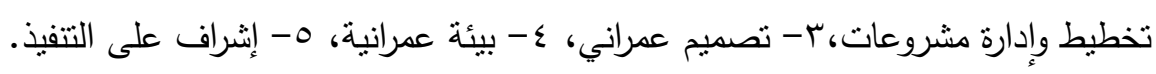

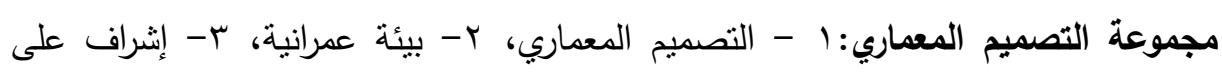

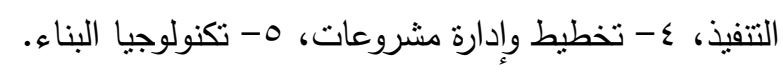

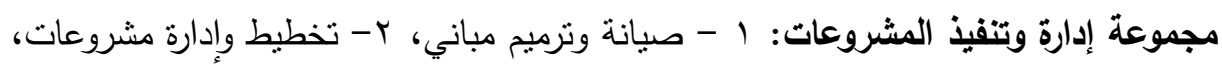

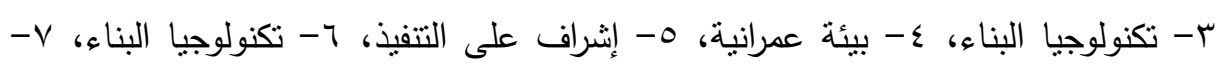

$$
\text { ترميمات المباني، 1- ترميم الآثار. }
$$


مجلة العلوم البيئية

معهد الدراسات والبحوث البيئية - جامعة عين شمس لبهن

التخصص العام مهندس معماري- التخصص الدقيق [ تصميم وتخطيط عمراني ]: جدول(ه): يبين مقترح شعبة مهندس معماري تخصص تصميم وتخطيط معماري

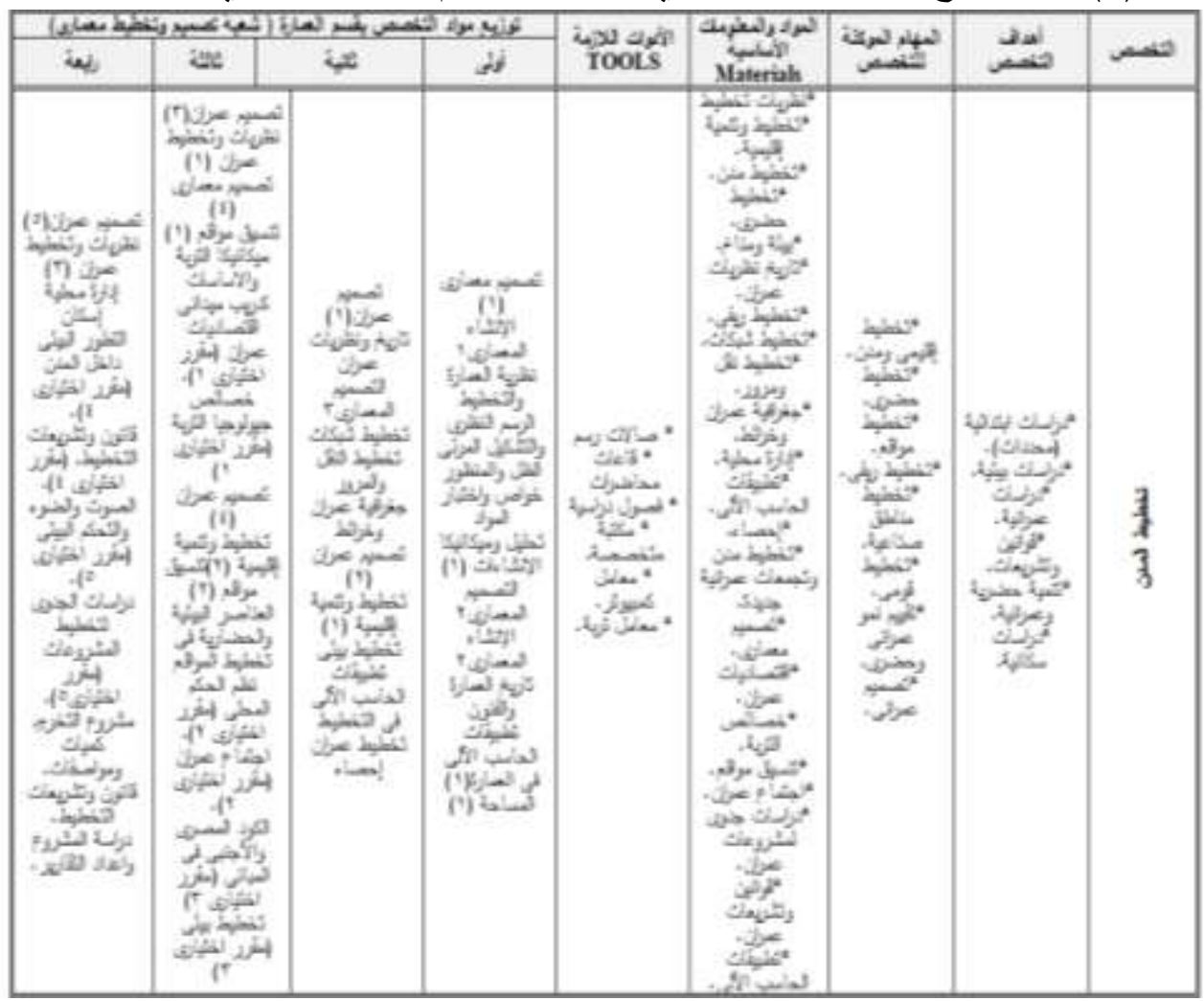


أحمد يحيب إسماعيل وآخرون

التخصص العام مهندس معماري - التخصص الدقيق [ تصميم معماري ] أو [ شعبة عامة ] جدول( ا): يبين مقترح شعبة مهندس معماري تخصص تصميم معماري

\begin{tabular}{|c|c|c|c|c|c|c|c|c|}
\hline \multicolumn{4}{|c|}{ 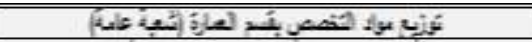 } & \multirow{2}{*}{$\begin{array}{c}4,30 \\
\text { TOOLLS }\end{array}$} & \multirow{2}{*}{ 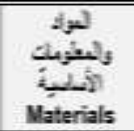 } & \multirow{2}{*}{ 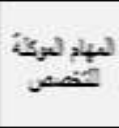 } & \multirow[b]{2}{*}{ آدالد المصص } & \multirow[b]{2}{*}{ تخصص } \\
\hline ري & ane & تدية & aj & & & & & \\
\hline 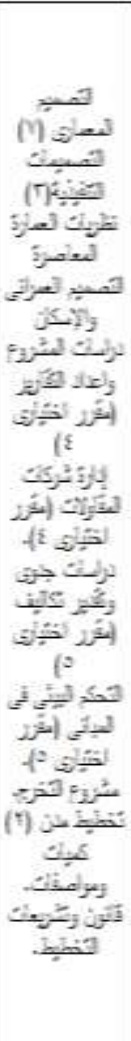 & 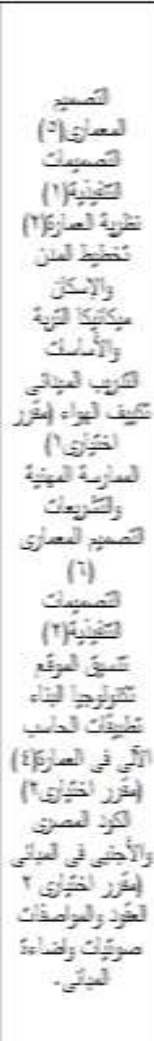 & 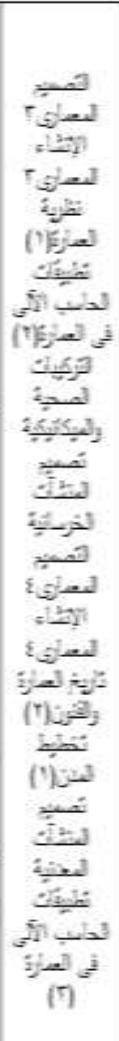 & 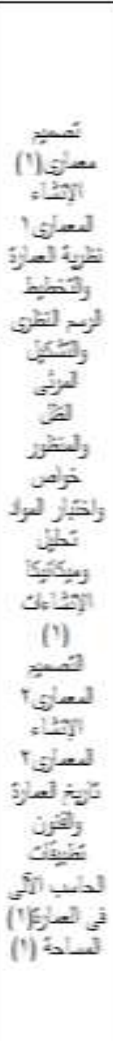 & 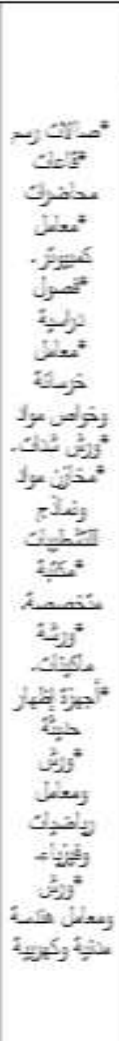 & لق & 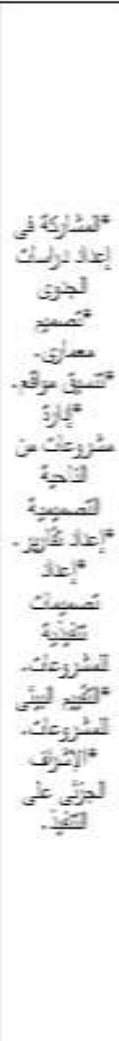 & " & $\begin{array}{l}\frac{7}{2} \\
\frac{3}{3}\end{array}$ \\
\hline
\end{tabular}


التخصص العام: مهند معماري - التخصص الدقيق إدارة تنفيذ لمشروعات العمرانية

جدول(V): يبين مقترح شعبة مهندس معماري تخصص إدارة تتفيذ المشروعات العمرانية

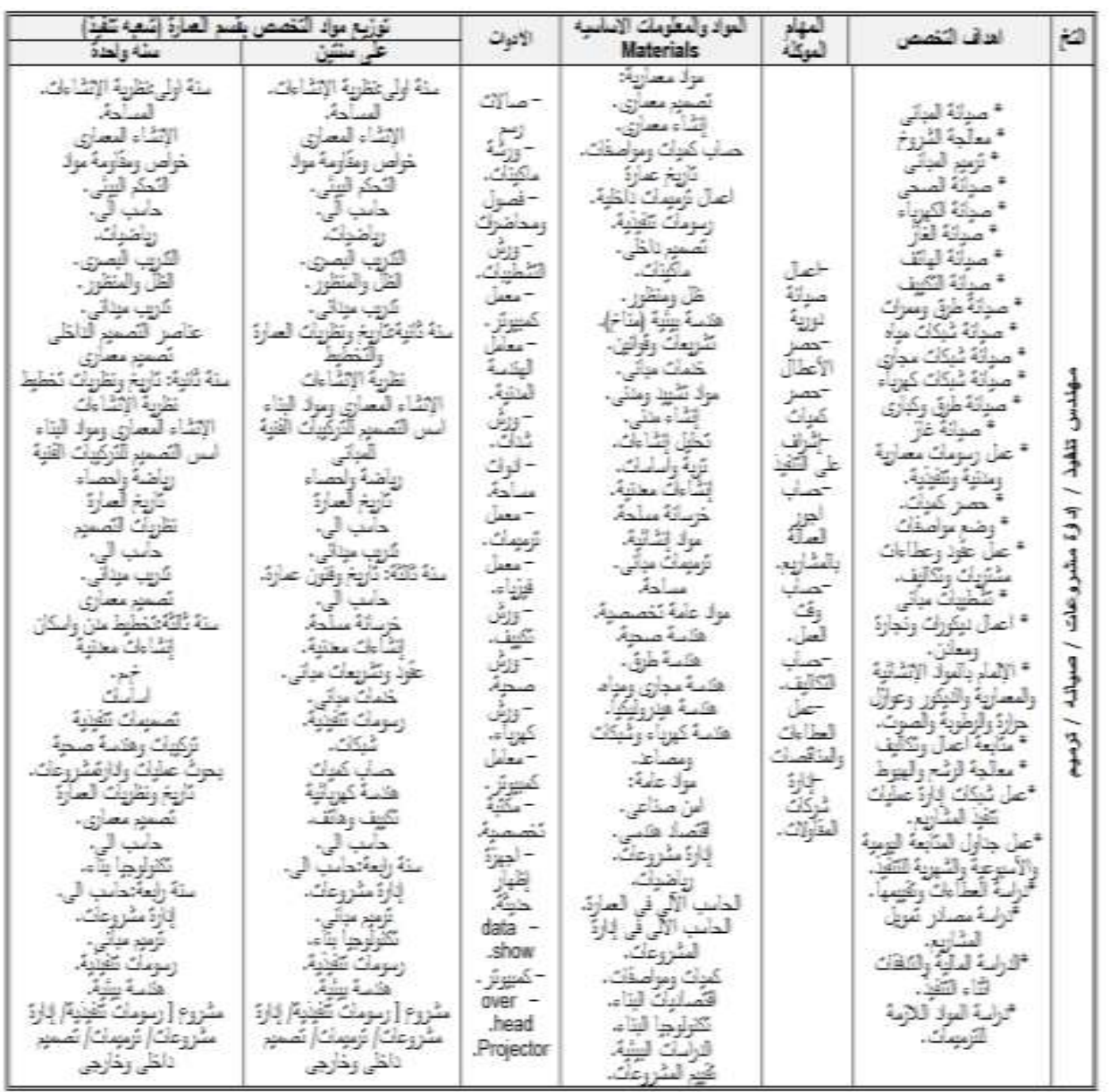


أحد تجارب تطوير المناهج الدراسية المحلية - قسم العمارة - المعهد العالي للهندسة بالشروق ( اكاديمية الشروق ) باستخدام نظام الايكم: انثئ المعرد العالي للهنسة عام 1990 وكانت عدد برامجه خمسة ( هندسة اتصالات - الهندسة الطبية -

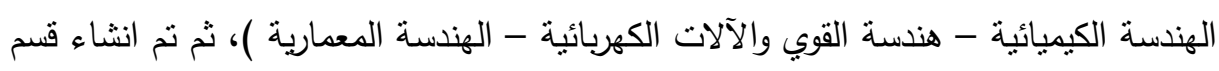

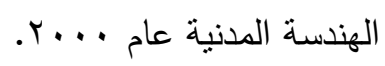

وأنشئ قسم العمارة بالمعهد بالاعتماد على المناهج الدراسية المعمارية بأقسام العمارة

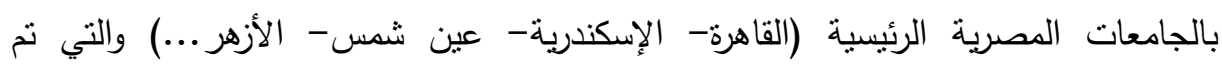

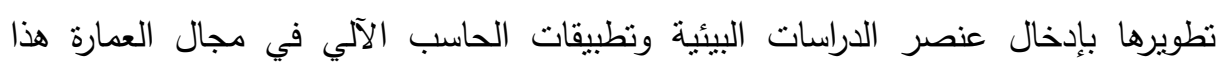

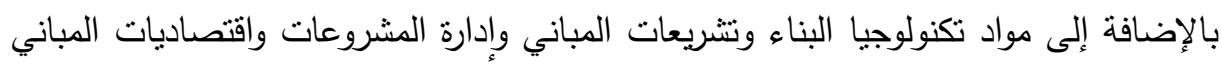

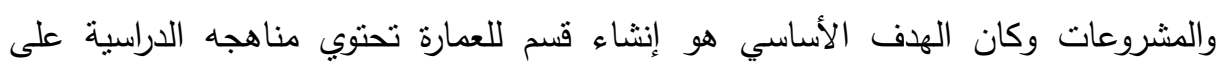

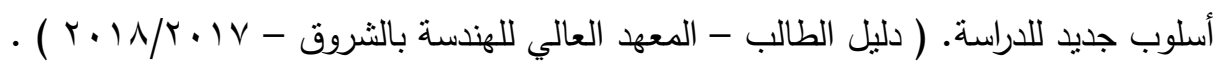

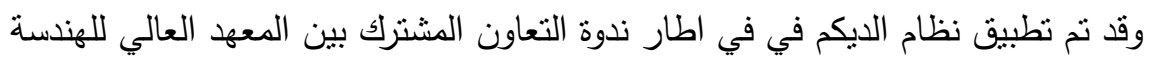

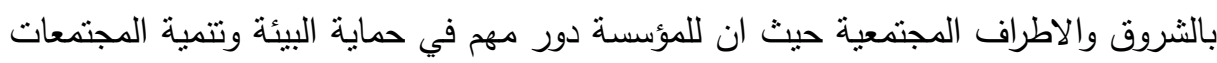
الدحيطة بها وتلبية احتياجاتها من خلال ما تمارسه من اشطة أو ما تقدمه من خدمات التهات

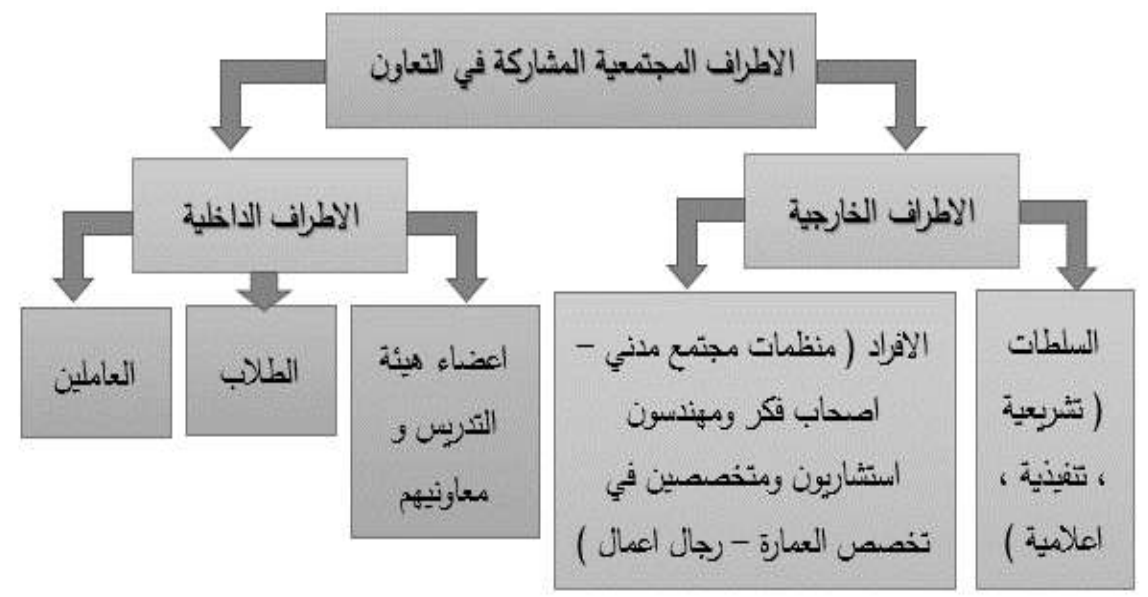

شكل(؟): الاطراف المجتمعية الششاركة في تجربة تطبيق نظام الديكم بالمعهد العالي للهنسة بالثروق 
حيث قام المعهر بقياس رضا الاطراف المجتمعية عن الانشطة التي قام بها المعهد

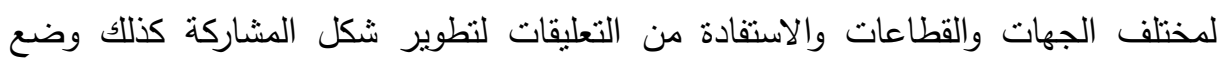
المقترحات من ضمن خطة مستقبلية لنطوير برامج الاقسام المختلفة ومنها قسم العمارة للنوافق

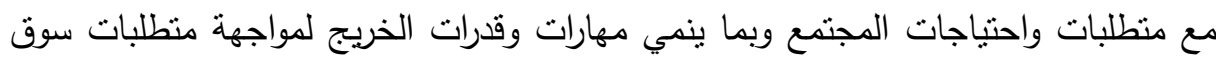

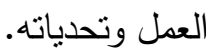

منهجية اعداد الخطة الاستراتيجية للتطوير : ( بروتوكول التعاون المشترك بين المعهد

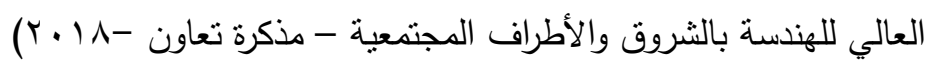
• • تشكيل فريق لاعداد وتطوير الخطة الاستراتيجية • عقد ورش عمل للتوعية بأهمية التخطيط الاستراتيجي وطرق تحليل البيئة الداخلية

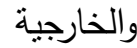

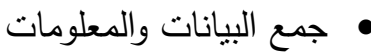

$$
\begin{aligned}
& \text { • تحليل الاستبيانات وتحديد احتياجات وتوقعات الاطراف المختلفة . }
\end{aligned}
$$$$
\text { • • عرض نتائج التحليل البيئي ومناقشتها مع الاطراف المختلفة }
$$

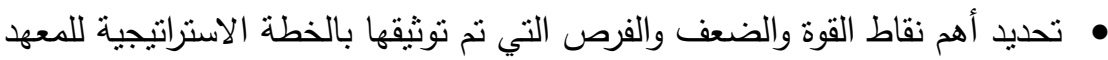
• مناقثنة الغايات والاهداف الاستراتيجية وارتباطها بالخطة الاستراتيجية للوزارة وأولويات

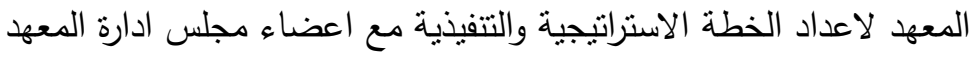
• وضع الخطة التنفيذية لتحقيق الغايات والأهداف الاستراتيجية للمعهد التهاه • • تم تحديد الية لمتابعة وتتفيذ الخطة الاستراتيجية والتنفيذية متطلبات مشاركة الاطراف المجتمعية في تصميم البرامج: يتطلب لمشاركة الاطراف المجتمعية في تصميم البرامج التعليمية المختلفة بالمعهد التعرف علي ما هيئة البرامج التعليمية

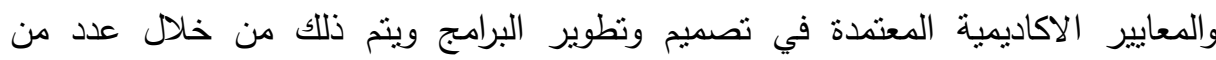

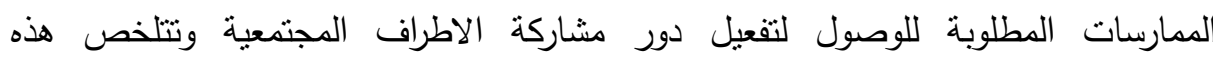
الممارسات في الاجابة علي مجموعة من الاستبيانات كالتالي: الاستبيان الخاص بالجهات لإنهات الموظقة للخريجين ( إجراءات متابعة الخريجين ).

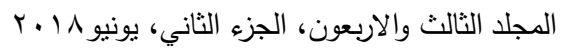


جدول(^): نتائج الاسنبيان الخاصبالجهات الموظفة للخريجين ( إجراءات متابعة الخريجين ) الباحث

\begin{tabular}{|c|c|c|c|c|}
\hline$\gamma$ & جزئي & نعم & العنصر & \\
\hline---- & $\%$ r. & $\% \wedge$. & 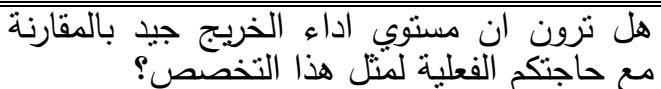 & -1 \\
\hline---- & $\% \varepsilon$. & $\% 4$. & 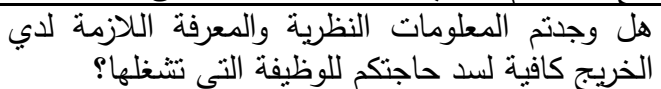 & $-r$ \\
\hline---- & $\% r$. & $\% \vee$. & 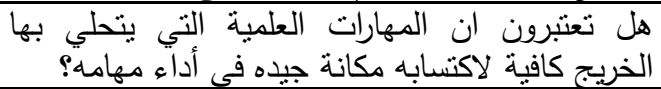 & $-\mu$ \\
\hline---- & $\% \varepsilon$. & $\% 7$. & 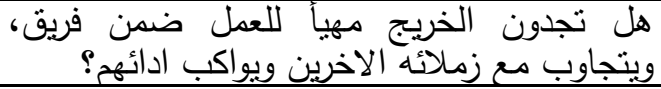 & $-\varepsilon$ \\
\hline$\% 1$. & $\% \varepsilon$. & $\% ०$. & العمل تعتبرون الخريج ملتزم بتتفيذ تعاليم رؤسائه في & -0 \\
\hline$\% r$. & $\% \varepsilon$. & $\% r$. & 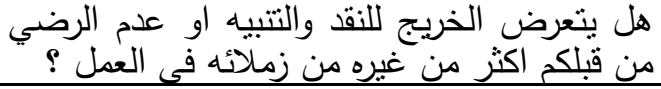 & -7 \\
\hline---- & $\% ०$. & $\% ०$. & 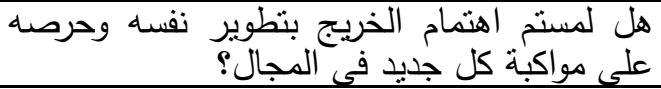 & $-\gamma$ \\
\hline$\% 1$. & $\% \varepsilon$. & $\% 0$. & العمل تعتبرون الخريج ملتزم بتتفيذ نعاليم رؤسائه في & $-\lambda$ \\
\hline---- & $\% 0$. & $\% 0$. & 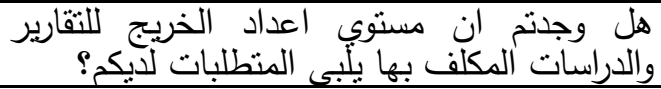 & -9 \\
\hline---- & $\% 1$. & $\% q$. & الحاجه؟ ترغبون بتوظيف مزيدا من خريجي قسمنا عند & -1 \\
\hline
\end{tabular}
جلول(9): نتائج استنيان فئات المجتمع - اجراءات تتفيذ مهام البرامج التعليمية في أحد الاقسام المعنية بالمعهد، الباحثى

\begin{tabular}{|c|c|c|c|c|}
\hline موافثِّ & موافئي & كوافيّ & العنصر & \\
\hline---- & $\% \varepsilon$. & $\% 4$. & 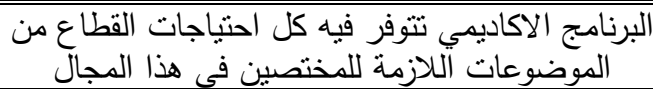 & 1 \\
\hline$\% 1$. & $\% r$. & $\% v$. & المعرفنة النظرية والعلميلّة التي توفرهات في هذا التخواد الدراسية في & r \\
\hline$\%$ r. & $\%$ \%. & $\% 0$. & المواد العلمية التي تتوفلفر في البرنات هذا المجال كافية لبناء & r \\
\hline$\% 1$. & $\% \varepsilon$. & $\% 0$. & 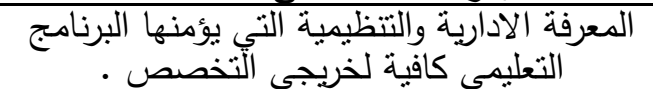 & $\varepsilon$ \\
\hline$\%$ \%. & $\% r$. & $\% \pi$. & خريجو هذا المعهد يتميزون عن غيرهم من الخريجين. & o \\
\hline
\end{tabular}

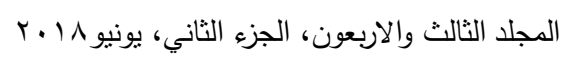




\section{انعكاس نتائج الاستبيانات علي تطوير برنامج قسم العمارة:}

جدول(• (1): تطوير برنامج قسم العمارة بناءا علي نتائج الاستبيانات في اطار تجربة الديكم .

الباحث:

\begin{tabular}{|c|c|}
\hline حال الi & هاًّ بألبرنامج : \\
\hline 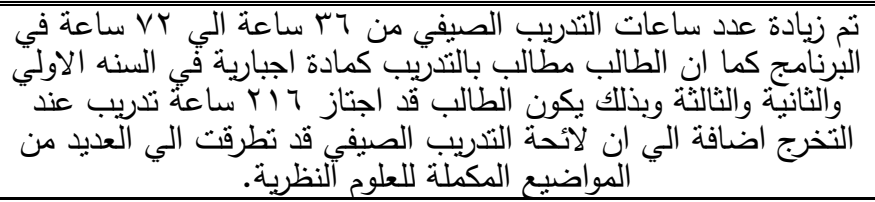 & 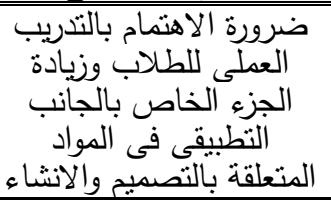 \\
\hline 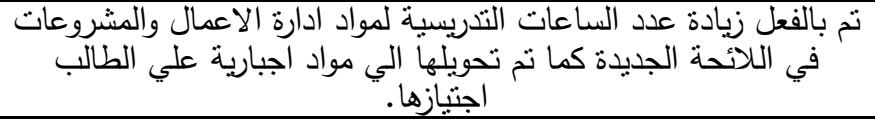 & 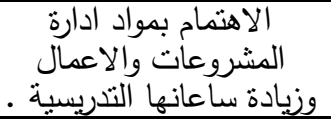 \\
\hline 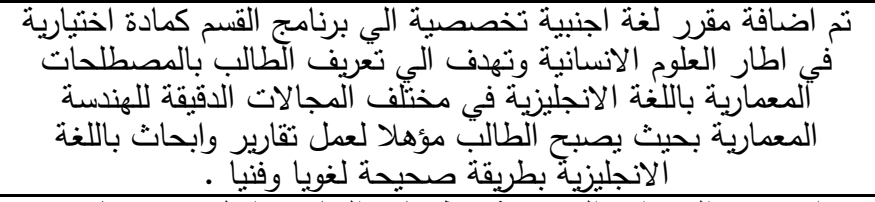 & 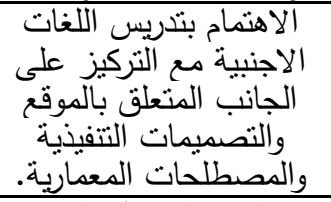 \\
\hline 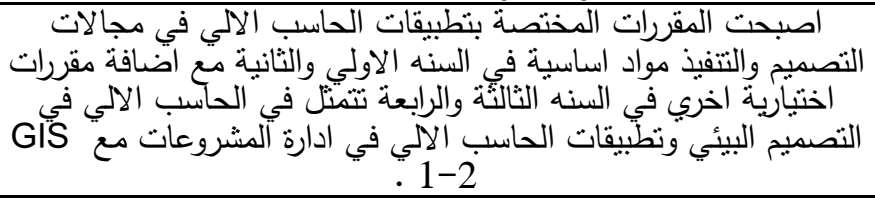 & 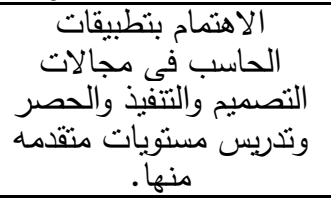 \\
\hline 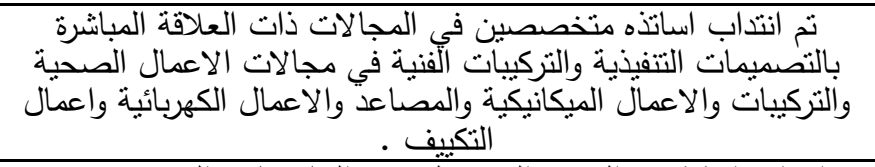 & الفنية لتنفق مادة التركيبات منظبات \\
\hline 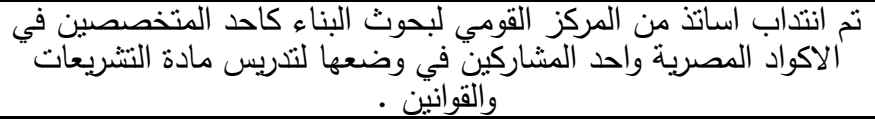 & 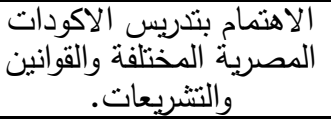 \\
\hline 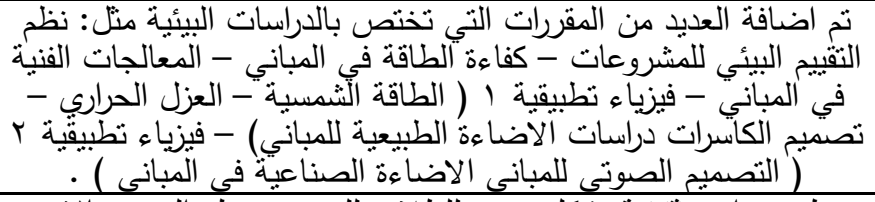 & تدريس نظم الطاقة الجديح فيدة \\
\hline تتظيم ندوات تثقيفية بشكل دوري للطلاب البناء واللتعريف بنظم الجودة والايزو & تدريس نظم الجودة والايزو \\
\hline 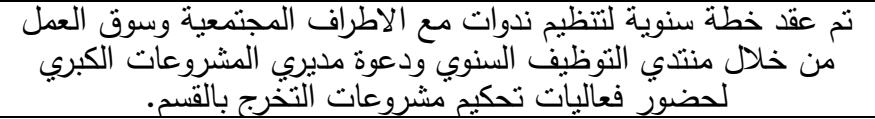 & ضرورة اعداد مؤتمرات \\
\hline
\end{tabular}

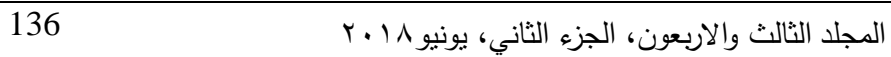




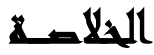

يخلص البحث لأهمية تحديث مناهج وبرامج التدريب بأقسام العمارة والتخطيط بما يتلاءم مع اتجاهات التتمية العمرانية وخطط التتمية بمصر وهذا من خلال:

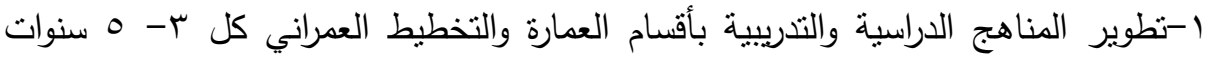
وباستخدام نظام الديكم أو أحد نظم التطوير الملائمة مع نوفير الدعم المالي والإمكانات اللازمة لتصميم وتطوير مناهج التعليم مع التدريب.

r-تصنيف التخصصات بأقسام العمارة والتخطيط لينسنى تخريج معماريين ذو درجات لفئ علمية وتدريبية ملائمة واحتياجات خطط التتمية العمرانية سواء للتصميم المعماري، إدارة

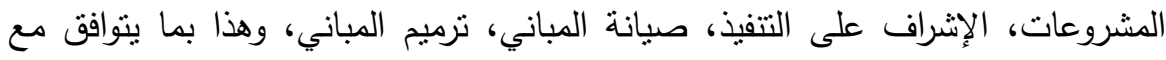
ميول ورغبات الطلاب أثناء العملية التعليمية من ملكات فنبة وتقنية في مختلف

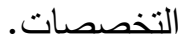

ب-تكامل أعداد هيئة التدريس والهيئة المعاونة مع إعداد الطلاب أثناء العطلية التعليمية. ع-التطوير المستمر لنظام الديكم كأداة وأسلوب لتطوير مناهج التعليم والتدريب بأقسام العمارة وهذا من خلال عمل دراسات مقارنة بينه وبين الأنظمة المختلفة وبما يتلاءم مع التطور في مجالات التنمية العمرانية. ه-تكامل العوامل الاجتماعية، البيئية، الاقتصادية، التراث الحضاري، والفكر العالمي في

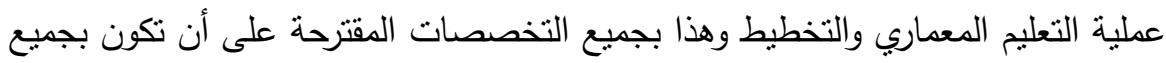
مناهجه التعليمية والتدريبية.

\section{2all}

Developing-A-Curriculum(DACUM) Workshop Report on Sustainable Urban Agriculture Enterprises ( December 3, 2012): Workshop Conducted By: Sustainable Agriculture Education (SAE) Collaborative, Contributing Collaborative Partners: Edmonds Community College National Science Foundation.

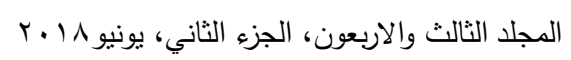


إبراهيم جواد كاظم(ع ( • ب): التوجه نحو الجودة والاعتمادية في التعليم المعماري - بحث

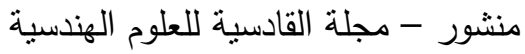

بروتوكول التعاون المشترك بين المعهد العالي للهندسة بالثروق والاطراف المجنمعية

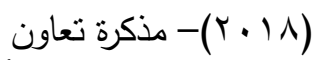

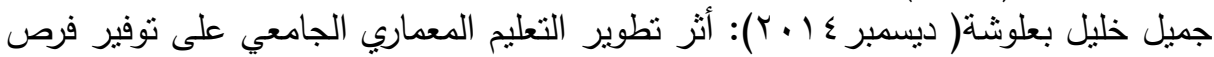

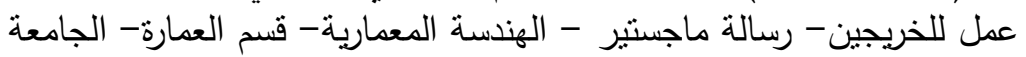

$$
\text { الإسلامية بغزة العزين }
$$

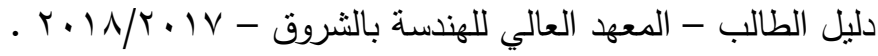

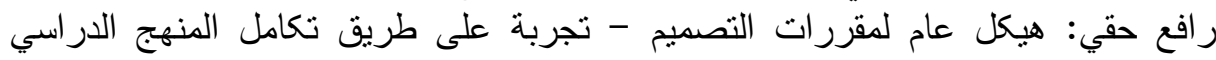

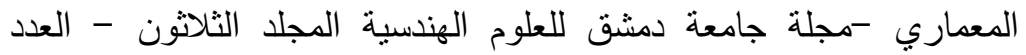

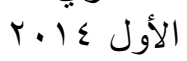

رائد بن منصور الدخيل: وسائل تطوير تعليم برمجة المشاريع المعمارية - دراسية حالة:

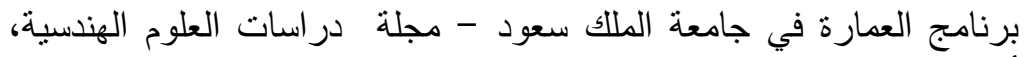

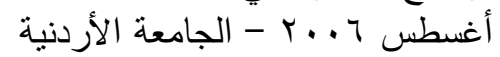

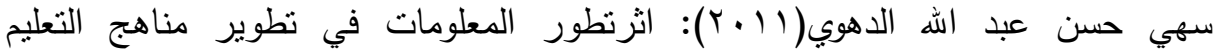

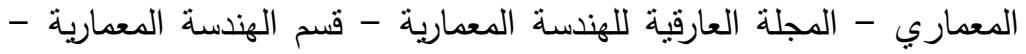

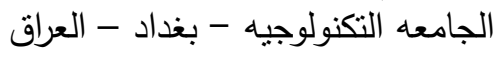

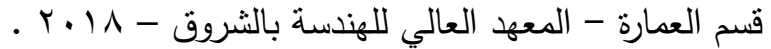

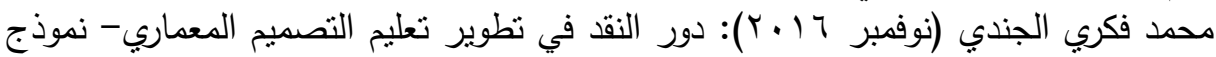

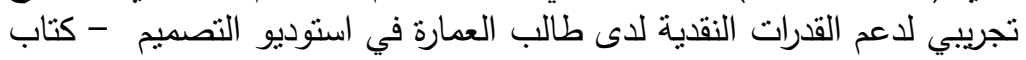

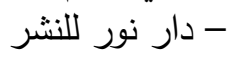

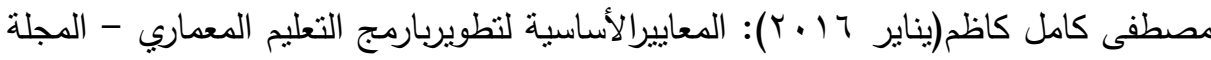

العارقية للهندسة المعمارية - قسم الهندسة المعمارية - الجامعه التكنولوجيه -

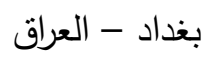

منال أحمد بماني بدوي(9 ج . ب): علاقة التعليم المعماري الجامعي بممارسة المهنة المعمارية

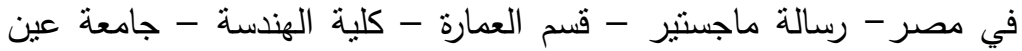

شمس في مس

Seet ,Iris(23 Jan 2008): Curriculum Development , Leaders in Education and Training for Sustained Growth in Africa , Director/Curriculum \& Educational Development Divisional Director/Curriculum \& Educational

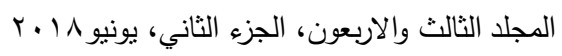


Development Institute of Technical Education Institute of Technical Education

Niebler JJason (December 3, 2012): Developing-A-Curriculum (DACUM) Workshop Report on Sustainable Urban Agriculture Enterprises, Sustainable Agriculture Education (SAE) Collaborative .

Overview of DACUM Job Analysis (October 2003): Ida M. Halasz, Ph.D., NIC Academy Division, September 1994 Revised by Thomas Reid, Ph. D., NIC Academy Division,. The NIC Information Center.

\title{
DEVELOPING THE PROGRAMS OF
}

\section{ARCHITECTURE \& PLANNING DEPARTMENT ACCORDING TO SUSTAINABLE URBAN DEVELOPMENT}

\section{Esmail, A. Y. ${ }^{(1)}$ and Abd el Hafez, M. M. M. ${ }^{(2)}$}

1) Department of Architecture, Factuality of Fine Art and Department of Architecture El-Shorouk Academy 2) Department of Architecture, Higher Institute of Engineering, Modern Academy

\begin{abstract}
According to the relationship between the universities and its societies whether providing by specialists of every field in order to society development.

So, the Egyptian Universities must be keeping up its education curriculums.

Now Egypt has several national ambitious projects such as create new cities, mega industrial and agricultural projects around all regions,
\end{abstract}

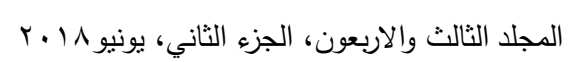


so the architecture and planning curriculums must be developed by 21 century requirements.

This scientific paper changes the traditional teaching methods and its contents to keeping up national, regional \& international requirements of market: then discusses these materials with bosses of the architecture and planning fields and the international similar systems.

Key words: Developing Programs - Architecture Department Planning Department - Sustainable Development - Egyptian Universities - Teaching Methods - Planning Curriculums. 